Research Article

\title{
Study on Crack Initiation and Propagation of New Corrosion Inhibitor during Stress Corrosion of Aluminum Alloy
}

\author{
Juan Du (D), Zi-ming Wei (D), Xu-dong Yang, Qing-mao Liu, Hai-peng Song, \\ Xue-lan Hu, and Xiang-yun Li
}

Civil Aviation University of China, Tianjin 300300, China

Correspondence should be addressed to Juan Du; dujuan247@163.com

Received 2 November 2019; Revised 31 December 2019; Accepted 7 January 2020; Published 28 March 2020

Academic Editor: Daniel Cozzolino

Copyright (c) 2020 Juan Du et al. This is an open access article distributed under the Creative Commons Attribution License, which permits unrestricted use, distribution, and reproduction in any medium, provided the original work is properly cited.

\begin{abstract}
In this paper, a novel method combining electrochemical impedance spectroscopy (EIS) and phase shift was used to systematically study the effect of corrosion inhibitor (sodium succinate, sodium dodecyl benzene sulfonate, and new corrosion inhibitor, namely, bis [2-amino-3-(dodecyl dimethyl quaternary ammonium) propyl]-propylamine dichloro) on crack initiation and propagation of aluminum alloy during the slow strain rate tensile process. Using a variety of characterization methods to verify the feasibility of using the new method for in-situ prediction, Kramers-Kronig transformations have been used to validate the experimental data obtained with the EIS measurements. The corrosion inhibition mechanism of these three kinds of inhibitors in the SSRT process was analyzed.
\end{abstract}

\section{Introduction}

Aluminum alloys are widely used in the aerospace field for aircraft fuselages, skins, and landing gear. The service environment of the aircraft is very complex. For example, the stress corrosion cracking (SCC) [1] behavior can easily occur in environments such as coastal areas, salt fog, and acid rain, which brings great risks to safety of flight. At present, the addition of corrosion inhibitors is commonly used and is economical methods for reducing stress corrosion. Therefore, it is of great significance to improve the reliability and safety of the aircraft by studying the corrosion initiation and propagation of corrosion inhibitors for aerospace aluminum alloys under mechanical-corrosion coupling and understanding the mechanism of corrosion inhibition.

Researchers have studied the mechanism of crack initiation and propagation in the SCC process and the corrosion inhibition mechanism of corrosion inhibitors. Petit et al. [2] have used impedance measurements during Slow Strain Rate Tests (SSRTs) of Type 304 stainless steel in boiling $44 \% \mathrm{MgCl}_{2}$ solution. They measured the phase at a particular frequency during the test and attempted to correlate crack initiation to changes in this phase, but there was not much research on electrochemical corrosion kinetics information in this process. Bosch [3] gave an equivalent circuit description of the crack impedance model and showed that the evolution of the impedance phase at certain frequencies may be related to the occurrence of SCC, establishing the possibility of inferring crack initiation using the phase-shift method. But, it does not give a good prediction of the crack obvious propagation of the alloy. Zhao et al. [4] used a high-resolution transmission electron microscope and transmission Kikuchi diffraction (TKD) characterization to understand the mechanism controlling SCC in Inconel 600 exposed to simulated PWR primary water conditions. It is believed that the dominant mechanism on SCC propagation is intergranular internal oxidation. The major precursors contributing to the SCC crack propagation are the intergranular $\mathrm{Cr}$ depletion, the formation of a porous oxide, and the prior cold-work and external load induced localized deformation around the crack tips. Seong et al. [5] studied the SCC behavior of sensitized aluminum alloy 5083 (AA5083) during the SSRT process in $3.5 \mathrm{wt} . \% \mathrm{NaCl}$ solution with and without the addition of $\mathrm{K}_{2} \mathrm{CrO}_{4}, \mathrm{Na}_{2} \mathrm{SiO}_{3}$, or $\mathrm{NaVO}_{3}$ as corrosion inhibitors. It became immune to IGSCC in the orientation 
tested when the added inhibitors shifted the OCP to a potential below the breakdown potential $\left(E_{\mathrm{b}}\right)$ of the $\beta$ phase. Therefore, a high rate of $\beta$-phase dissolution, which is essential for IGSCC, can be prevented by shifting the OCP below the $E_{\mathrm{b}}$ of the $\beta$ phase. Fang et al. [6] studied caffeic acid, 2-isopropyl-5-methylphenol (IPMP), and 3,4,5-trihydroxybenzoic acid by cyclic voltammetry using a multiwalled carbon nanotube-modified glassy carbon electrode. The electrochemical properties of aromatic active compounds of seven plant extracts are reported, and their redox behavior under different environments and different $\mathrm{pH}$ conditions is reported. The results indicate that in the end hydrogen substitution and oxidation reaction of the benzene ring, insoluble compounds are formed to hinder the progress of corrosion of the metal surface, which is attributable to the chemical nature of the aromatic structure of these compounds. Mohammad et al. [7] studied the corrosion inhibition mechanism of mild steel in acidic solution and in the presence of two cationic gemini surfactants. These are two surfactants having 12-carbon hydrophobic tails: one with a tetramethylene spacer and the other one with the same spacer containing two hydroxyl groups. EIS and polarization and electrochemical noise measurements revealed superior corrosion inhibition of hydroxyl functional surfactant compared with its counterpart with no hydroxyl group. Rifat et al. [8] showed that Citrus aurantium leaves extract acts as efficient corrosion picking inhibitor on carbon steel (CS) in $1 \mathrm{M}$ corrosive media. The extract showed maximum IE of $81.2 \%$ at the presence of $20 \%$ in v/v during $3 \mathrm{~h}$ at $25^{\circ} \mathrm{C}$. The IE\% increased with increasing temperature. Ea decreases in presence of studied plant extract which indicates the chemisorption of the inhibitor molecules on the CS surface. C. aurantium leaves extract adsorbs on CS surface approbate to the Langmuir isotherm. Salman et al. [9] displayed a Schiff base derivative which has nitrogen, oxygen, and sulfur atoms as corrosion inhibitor for MS "mild steel" in $1 \mathrm{M} \mathrm{HCl}$ "hydrochloric acid" solution. The weight loss and SEM "scanning electron microscope" studies showed that inhibitors have the ability to prevent the alloy surface from corrosive solution by adsorbing on MS surface to form the stable adsorbed layer that results in the higher inhibition efficiency. The inhibition influence of the synthesized inhibitor was increased parallel with increasing concentration and decrease with rising temperature degrees. Ahmed [10] studied the electrochemical performance of a novel organic corrosion inhibitor 6-(4-hydroxyphenyl)-3mercapto-7,8-dihydro- $[1,2,4]$ triazolo $[4,3-\mathrm{b}][1,2,4,5]$ tetrazine [HT3], for mild steel in $1 \mathrm{M}$ hydrochloric acid by potentiodynamic curves. The experimental results show that the investigated inhibitor [HT3], which can effectively retard the corrosion process that occurs to mild steel with a hydrochloric acid solution by providing a protective coating for the mild steel that, can be weakened by increasing the temperature. Qusay et al. [11] conducted the synthesis of novel thiosemicarbazone, namely, 2-(2,4-dimethoxybenzylidene) hydrazinecarbothioamide (DMBHC), and the chemical structure was elucidated. The EIS results revealed that thiosemicarbazone demonstrated the highest inhibition efficiency of $94.86 \%$, at a concentration of $0.5 \mathrm{mM}$. The impact of temperature on the mechanism of inhibition of the new synthesized inhibitor of the surface of $\mathrm{MS}$ in $1 \mathrm{~N} \mathrm{H}_{2} \mathrm{SO}_{4}$ was investigated at various temperatures $\left(30-60^{\circ} \mathrm{C}\right)$, where the inhibitive efficiency diminished with increasing temperatures.

In summary, there are many researches on the SCC process at present; however, few researchers used electrochemical impedance spectroscopy combined with phase shift to predict in situ the effect of corrosion inhibitor on variation law of crack of 7000 series aluminum alloy during the SSRT process. Therefore, in this paper, two traditional corrosion inhibitors (sodium succinate and sodium dodecyl benzene sulfonate) and a new type of amide-type Gemini quaternary ammonium surfactant (Bis [2-amino-3-dodecyl dimethyl quaternary ammonium]-propylamine dichloro) have been systematically studied by using this method of in situ prediction of crack initiation and propagation in the SSRT process. The effect of these three inhibitors on the crack initiation and propagation of aluminum alloy is discussed, and the corrosion inhibition mechanism is predicted.

The advantage of the EIS method is that it can obtain impedance spectra at different frequencies and times and can obtain more information of electrochemical kinetic and electrode interface structure, but it cannot directly reflect the change of crack initiation and propagation time. The phase shift method can predict the crack initiation and obvious propagation time after the data are processed, but the corresponding electrochemical kinetic information cannot be obtained. Compared with [3], which used the phase shift method to detect the SCC in various corrosion environments and load conditions, the new method can be used to analyze the crack initiation and propagation of aluminum alloy in the SSRT process and to further understand the changes of electrochemical kinetics in these processes.

\section{Experimental}

2.1. Materials and Samples. In this experiment, 7A04 aluminum alloy was selected as the object of study. This experiment is a SSRT test. 7A04 aluminum alloy sheet tensile specimens are processed with reference to national standard GB/T 228-2002 and industry standard HB7235-95.

The surface of 7A04 aluminum alloy sheet tensile specimen was cleaned with anhydrous ethanol and acetone in order to remove the oil stain and impurities on the surface of the sample. The unmeasured part of the sample was insulated and sealed with silicone rubber. After the silicone rubber was completely solidified, the specimen was sealed again with electrical insulating tape.

2.2. Experimental Method. The experiment was conducted under two different conditions:

(1) The corrosion inhibitor was added to the 3.5 wt. $\%$ $\mathrm{NaCl}$ solution with $\mathrm{pH} \sim 1$, and the tensile rate was $3 \mu \mathrm{m} / \mathrm{min}$ (SSRT)

(2) The corrosion inhibitor was added to the $3.5 \mathrm{wt} . \%$ $\mathrm{NaCl}$ solution with $\mathrm{pH} \sim 1$, no tensile stress 
At intervals of 30 minutes, electrochemical measurements were carried out on the samples under the condition of tensile stress and no tensile stress.

2.3. Electrochemical Measurement. A three-electrode system was used for electrochemical measurement (Figure 1). The working electrode was the measured part of 7A04 aluminum alloy specimen, the reference electrode was an $\mathrm{Ag} / \mathrm{Ag}^{+}$ electrode, and the auxiliary electrode was a graphite rod $[12,13]$. Electrochemical measurements were performed in 3.5 wt. $\% \mathrm{NaCl}$ solution with $\mathrm{pH} \sim 1$.

2.4. SEM Morphology Observation and EDS Analysis. After tensile fracture, the measured part of the sample was cut, soaked with alcohol, and then cleaned with acetone and then cleaned for 20 minutes using the ultrasonic cleaner with deionized water. Then, the fracture surface was wiped with alcohol cotton ball to remove the corrosion product. Finally, the fracture surface was washed with deionized water and dried by cold air. The fracture morphology was observed by the Hitachi S-3400N electron scanning microscope and analyzed by EDS.

2.5. Metallographic Analysis. After cutting, embedding, grinding, polishing, and preetching the sample, the sample is placed under the Zeiss microscope to observe the surface of the aluminum alloy. The etching solution is the mixed acid aqueous solution (Dix-Kener etching solution).

2.6. Infrared Spectroscopy Analysis. Infrared spectrum analysis was performed on the synthesized products to determine and verify the composition of the synthesized products. The scanning range is in the mid-infrared range $\left(500 \mathrm{~cm}^{-1}-4000 \mathrm{~cm}^{-1}\right)$, and the analysis is performed using a Fourier-transform infrared spectrometer.

2.7. Novel Method Combining EIS and Phase Shift. The phase shift method is to measure the specimen every half hour under the condition of tensile stress and no tensile stress, respectively. The phase shift-frequency diagram is used to analyze the law of crack initiation and crack propagation. The process is as follows. It is carried out in the open circuit for $30 \mathrm{~min}$ to stabilize the system before the EIS and phase method. After the tensile test start, the EIS measurements of the specimens under loading and unloaded stress are carried out every $30 \mathrm{~min}$, the frequency range is measured in the frequency range of $10 \mathrm{MHz}-100 \mathrm{kHz}$, and then the phase angle-frequency diagram is obtained. After the test is finished, selecting a fixed frequency for the obtained data, obtaining the variation curve of the phase angle over time at the fixed frequency, and obtaining the two phase angle-time curves under the loading stress and the unloaded stress, and then performing the difference value on the same moment, so that the phase shift-time curve can be obtained (phase shift $=$ phase $_{\text {stressed }}-$ phase $\left._{\text {non-stressed }}\right)$. The illustration is shown below. Through the phase shift-time curve, the time of crack initiation and obvious propagation can be inferred intuitively.

Bosch [3] mainly considered the evolution of $1 \mathrm{~Hz}$ and $10 \mathrm{~Hz}$ frequency phase shift to study the change of SCC. However, in this experiment, some errors cannot be avoided in the low frequency data itself, which is due to the longtime of electrochemical measurement in low frequency band. Therefore, the frequency shift of $10 \mathrm{~Hz}, 100 \mathrm{~Hz}$, and $1000 \mathrm{~Hz}$ is selected to analyze. It can be seen from the later experiments that although the range of phase shift at the frequency points of $100 \mathrm{~Hz}$ and $1000 \mathrm{~Hz}$ is relatively weak, it can still be observed that there are obvious changes in the phase shifts at some times. Therefore, selecting phase shifts of $10 \mathrm{~Hz}$, $100 \mathrm{~Hz}$, and $1000 \mathrm{~Hz}$ for analysis can better study the changes of cracks in the SCC process.

2.8. Synthesis of Novel Corrosion Inhibitor. Add $50 \mathrm{ml}$ dichloromethane as solvent in a beaker, $14.1 \mathrm{~g}$ chloroacetyl chloride was dissolved in dichloromethane, and $3.7 \mathrm{~g}$ of 3propylenediamine was dissolved in $20 \mathrm{~mL}$ dichloromethane. Under the condition of ice bath and stirring, the beaker was slowly dripped into the beaker at a speed of five seconds and one drop. After the dripping was finished, the temperature was increased and reacted in a water bath at $35^{\circ} \mathrm{C}$ for 5 hours. Then, in a water bath at $60^{\circ} \mathrm{C}$, a rotating evaporator was used to decompress for $1.5 \mathrm{~h}$ to remove the solvent and excess chloroacetyl chloride. The residual was dissolved in deionized water of $60^{\circ} \mathrm{C}$ for 8 hours at room temperature, then filtered, and the crystal was dried. The white crystal intermediate $4.9 \mathrm{~g}$ (1:3- dichloroacetamide) propylamine) was obtained. In step 1, $4.9 \mathrm{~g}$ propylamine was dissolved in $50 \mathrm{ml}$ ethyl acetate and $13.3 \mathrm{~g}$ dodecyl dimethyl tertiary amine was added and stirred at room temperature for 16 hours and then distilled for 1.5 hours in a $75^{\circ} \mathrm{C}$ water bath to remove the solvent and excess dodecyl dimethyl tertiary amine. Dissolve the residue with n-hexane, filter it, dry it out, recrystallize the residue with ethyl acetate twice, and naturally dry it to a constant weight. A white wax of $9.3 \mathrm{~g}$, namely, bis [2-amino-3-(dodecyl dimethyl quaternary ammonium) propyl] -propylamine dichloro, was obtained. The synthesis route is shown in Figure 2.

\section{Results and Discussions}

3.1. Structure Characterization of New Corrosion Inhibitor. The synthesized surfactants were measured by infrared spectroscopy, and the results are shown in Figure 3. As shown in Figure 1(b), N-H bond vibrational peak is at $3385 \mathrm{~cm}^{-1}$ and $3203 \mathrm{~cm}^{-1}$. The vibrational peak of C-O bond is in $1662 \mathrm{~cm}^{-1}$ amide-base. C-N bond vibrational peak in the amide group is at $1270 \mathrm{~cm}^{-1}$ [14]. The two strong absorption peaks at $2920 \mathrm{~cm}^{-1}$ and $2852 \mathrm{~cm}^{-1}$ are characteristic vibrational peaks of long-chain carbon. The characteristic vibration peak of $\mathrm{C}-\mathrm{H}$ is $1466 \mathrm{~cm}^{-1}$. The characteristic peaks of C-C, C-N, and C-Cl are between $1050 \mathrm{~cm}^{-1}$ and $500-700 \mathrm{~cm}^{-1}$ [15]. According to the results of infrared spectroscopy, it was found that the product contains long carbon chain, $-\mathrm{CH}_{3}, \mathrm{C}=\mathrm{O}, \mathrm{C}-\mathrm{Cl}$ bond, etc. Prove that the 


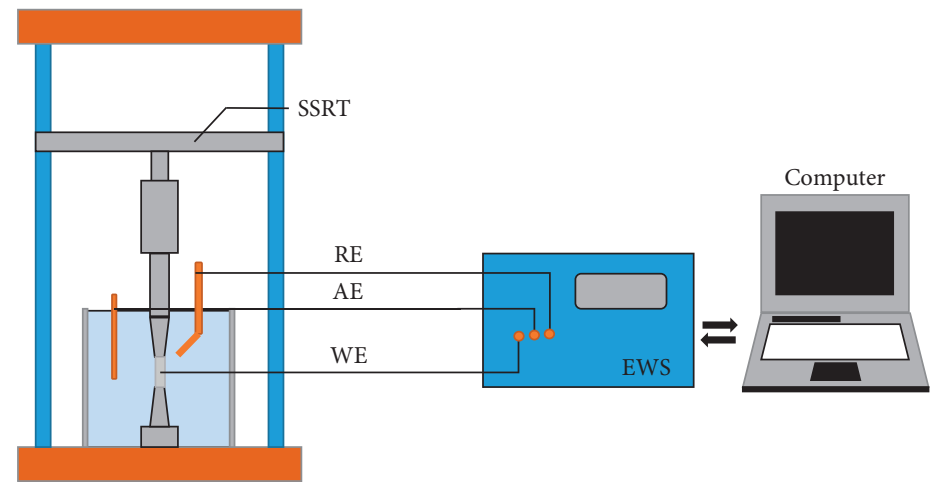

(a)

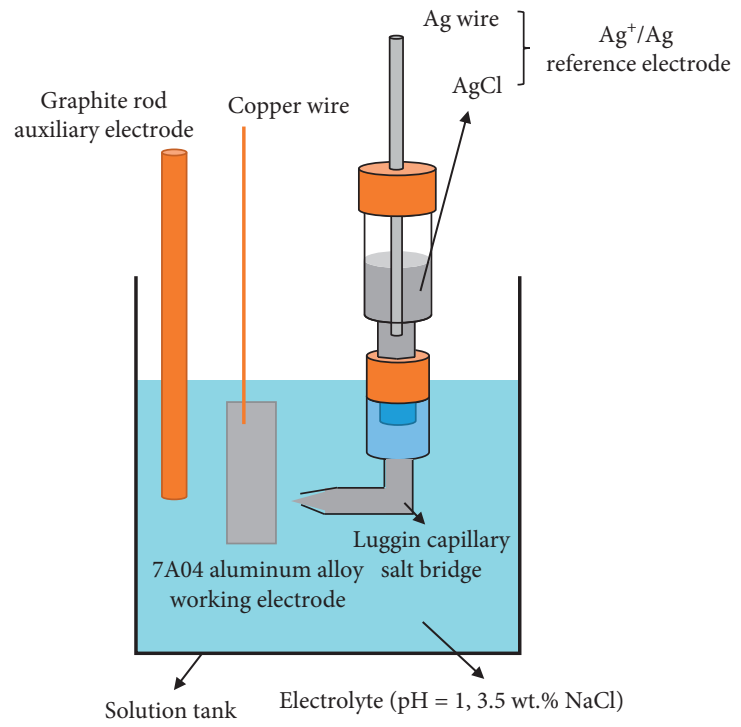

(b)

Figure 1: Schematic diagram of the experimental setup and three-electrode cell.

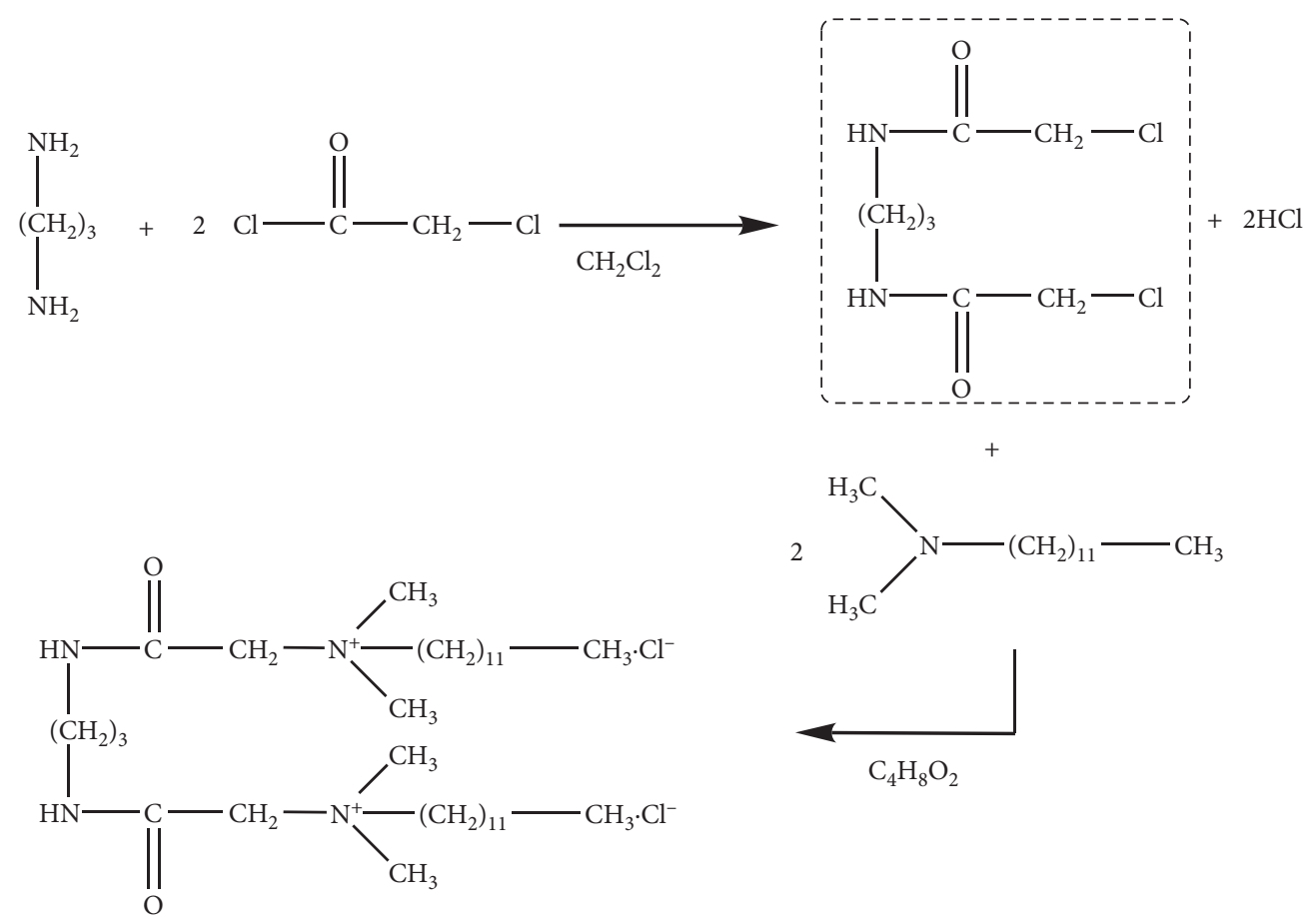

FIgURE 2: Synthetic route.

synthetic product is bis [2-amino-3-(dodecyl dimethyl quaternary ammonium) propyl]-propylamine dichloro.

After testing [16], the new corrosion inhibitor has higher corrosion resistance under acidic environment. However, its resistance to stress corrosion is not clear, so a new type of corrosion inhibitor was selected for stress corrosion test in this paper.

3.2. SEM Morphology Observation. In order to study the effect of different corrosion inhibitors on the stress corrosion susceptibility of aluminum alloy, the fracture surface was observed by SEM, as shown in Figure 4.

Figure 4 shows the fracture morphology of the sample under different conditions. In the condition that no corrosion inhibitor is added, there are "mud"-like corrosion products and corrosion pits at the fracture, which are mixed fractures. (B) With the addition of SDBS, the fracture is massive and belongs to brittle intergranular fracture. (C) With the addition of sodium succinate, the fracture surface is pitted but the degree of corrosion is weak. (D) With the addition of new corrosion inhibitor, the 


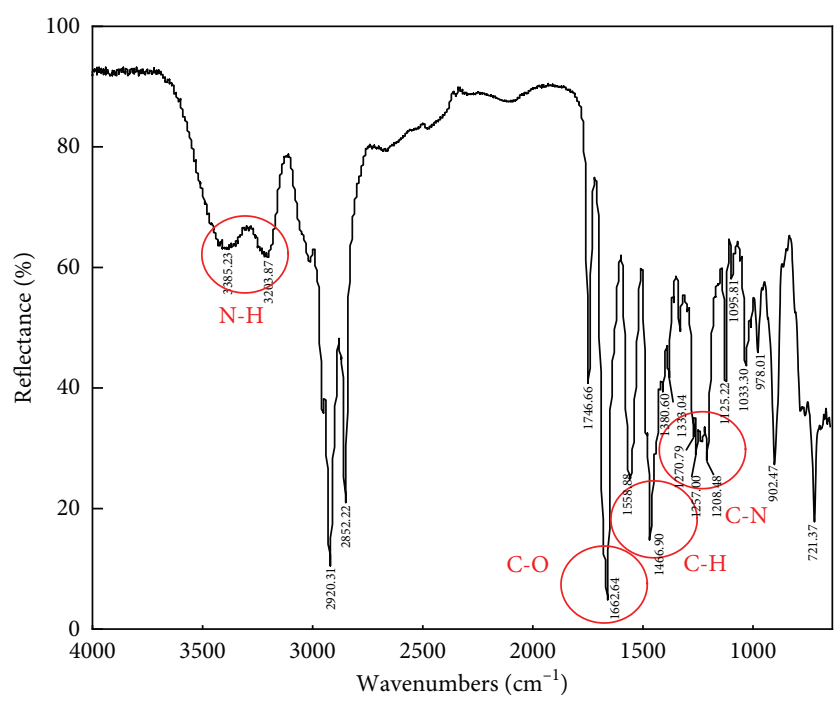

Figure 3: Synthetic product infrared spectrum.

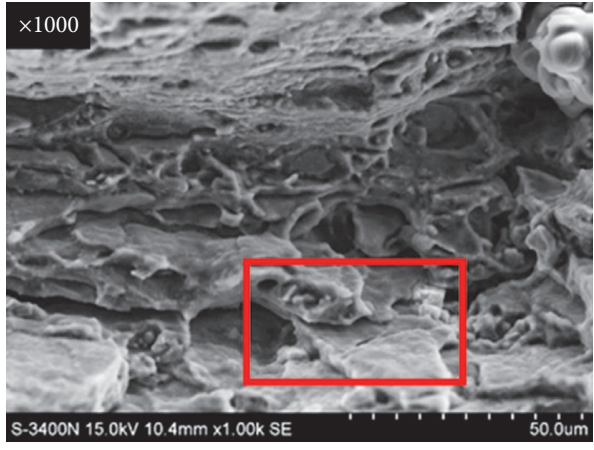

(a)

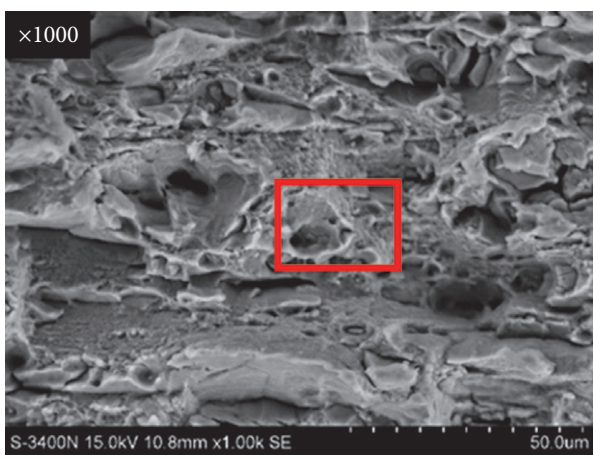

(c)

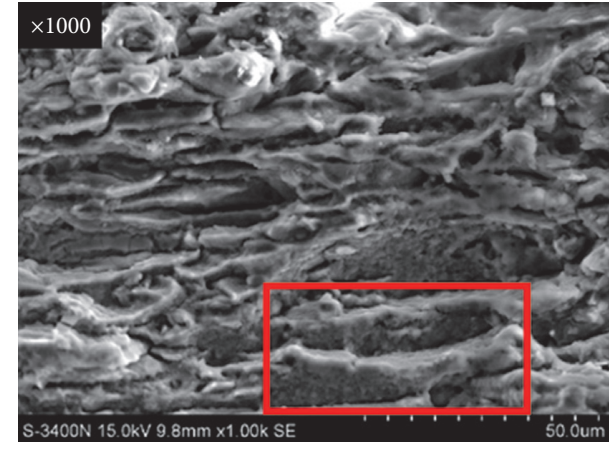

(b)

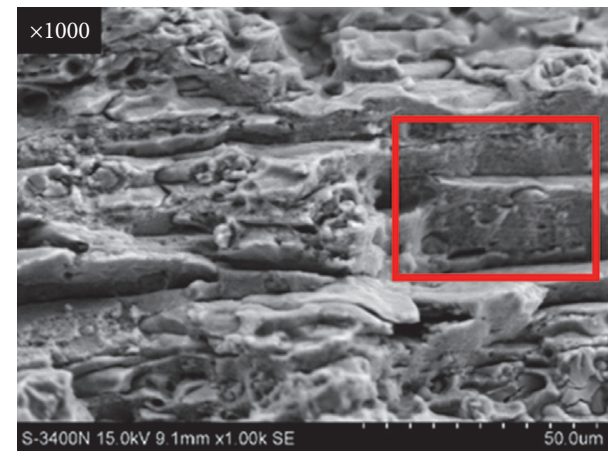

(d)

FIGURE 4: SEM images of the fracture morphology ( $\times 1000$ ): (a) without inhibitor. (b) $0.5 \mathrm{~g} / \mathrm{L}$ SDBS. (c) $7.5 \mathrm{~g} / \mathrm{L}$ sodium succinate. (d) $0.6 \mathrm{~g} / \mathrm{L}$ new corrosion inhibitor.

fracture surface is massive and has brittle intergranular fracture characteristics.

Therefore, in combination with the relevant literature [17] and SEM pictures, it can be inferred that the stress corrosion mechanism of 7A04 aluminum alloy in $3.5 \mathrm{wt} . \%$ $\mathrm{NaCl}$ solution of $\mathrm{pH}=1$ is mainly caused by anodic dissolution, not mainly caused by hydrogen embrittlement. After the corrosion inhibitor was added, the morphology of the fracture surface changed obviously and the grain of the fracture surface changed from disorderly to uniform. In addition, there was a significant change in the fracture mode, which was changed from the mixed type to the single-type fracture.

3.3. Study on Crack Initiation and Propagation Process of Corrosion Inhibitor during Stress Corrosion by EIS. EIS of this process was measured in situ every $30 \mathrm{~min}$. The whole tensile 

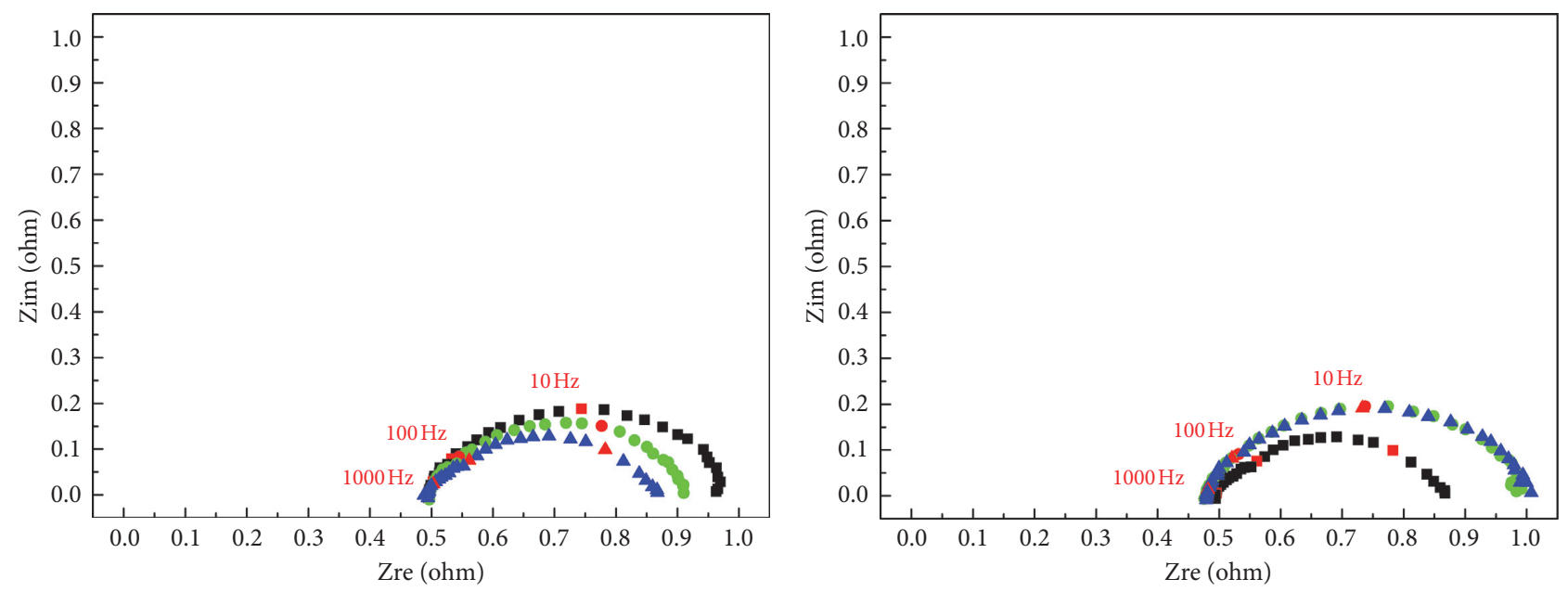

Without inhibitor

- $0 \mathrm{~h}$

- $0.5 \mathrm{~h}$

$\Delta 1.0 \mathrm{~h}$

(a)

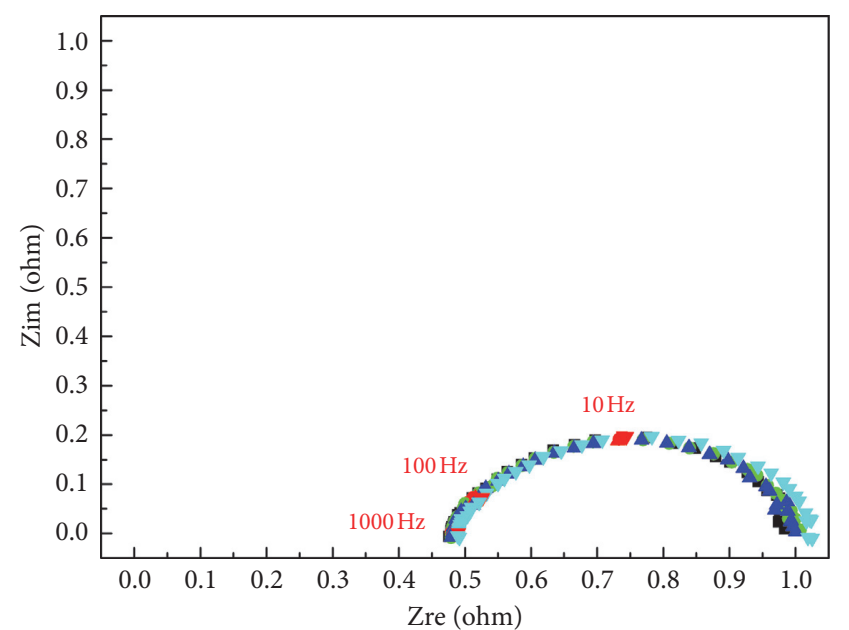

Without inhibitor

- $1.0 \mathrm{~h}$

- $1.5 \mathrm{~h}$

$\Delta 2.0 \mathrm{~h}$

(b)

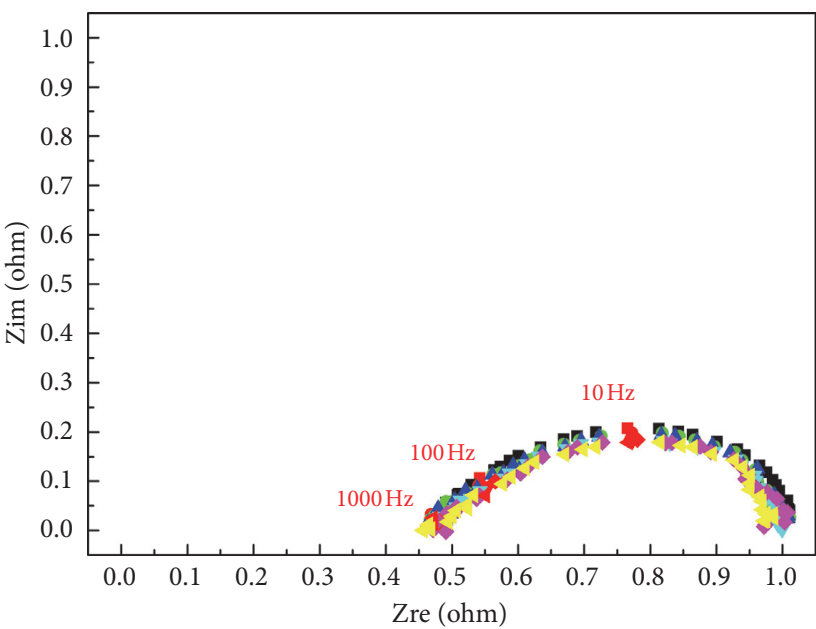

Without inhibitor

$\begin{array}{ll}\text { - } 1.5 \mathrm{~h} & \Delta 2.5 \mathrm{~h} \\ \text { - } 2.0 \mathrm{~h} & \checkmark 3.0 \mathrm{~h}\end{array}$

\begin{tabular}{|c|c|}
\hline Without inhibitor & \\
\hline - $3.5 \mathrm{~h}$ & $\nabla 5.0 \mathrm{~h}$ \\
\hline - $4.0 \mathrm{~h}$ & - $5.5 \mathrm{~h}$ \\
\hline$\Delta 4.5 \mathrm{~h}$ & $\triangleleft 6.0 \mathrm{~h}$ \\
\hline
\end{tabular}

(c)

(d)

Figure 5: Nyquist diagrams at different times without adding corrosion inhibitor: (a) $0-1.0 \mathrm{~h}$. (b) $1.0 \mathrm{~h}-2.0 \mathrm{~h}$. (c) $1.5 \mathrm{~h}-3.0 \mathrm{~h}$. (d) $3.5 \mathrm{~h}-6.0 \mathrm{~h}$.

stage was divided into four periods: metal dissolution stage, crack initiation stage, dynamic equilibrium stage, and crack propagation stage. The law of crack initiation and propagation in this time period was analyzed by EIS.

3.3.1. No Corrosion Inhibitor Added. It can be seen from Figure 5(a) that the capacitance arc decreases with time between 0 and $1 \mathrm{~h}$, indicating that the oxide film on metal surface dissolves under the action of acid solution. The dissolution and pitting of oxide film lead to the decrease of capacitance arc. Figure 5(b) is between 1.0 and $1.5 \mathrm{~h}$, and the capacitance arc increases with time, indicating that cracks on the surface of the metal begin to appear at $1 \mathrm{~h}$. Figure 5(c) is between 1.5 and $3.5 \mathrm{~h}$, the capacitance arc remains basically unchanged, the capacitance arc increases due to the crack initiation and the repassivation of metal, and the dissolution of metal in acid solution leads to the decrease of capacitance arc. This trend of increase and decrease reached a dynamic equilibrium during this period. Figure $5(\mathrm{~d})$ is between 3.5 and $6.0 \mathrm{~h}$, the capacitance arc decreases with time, which indicates that the increasing trend of capacitance arc caused by crack propagation is smaller than that caused by metal dissolution. This is due to the crack propagation resulting in more metal surface contact with acid solution, thus accelerating the dissolution of metals. 

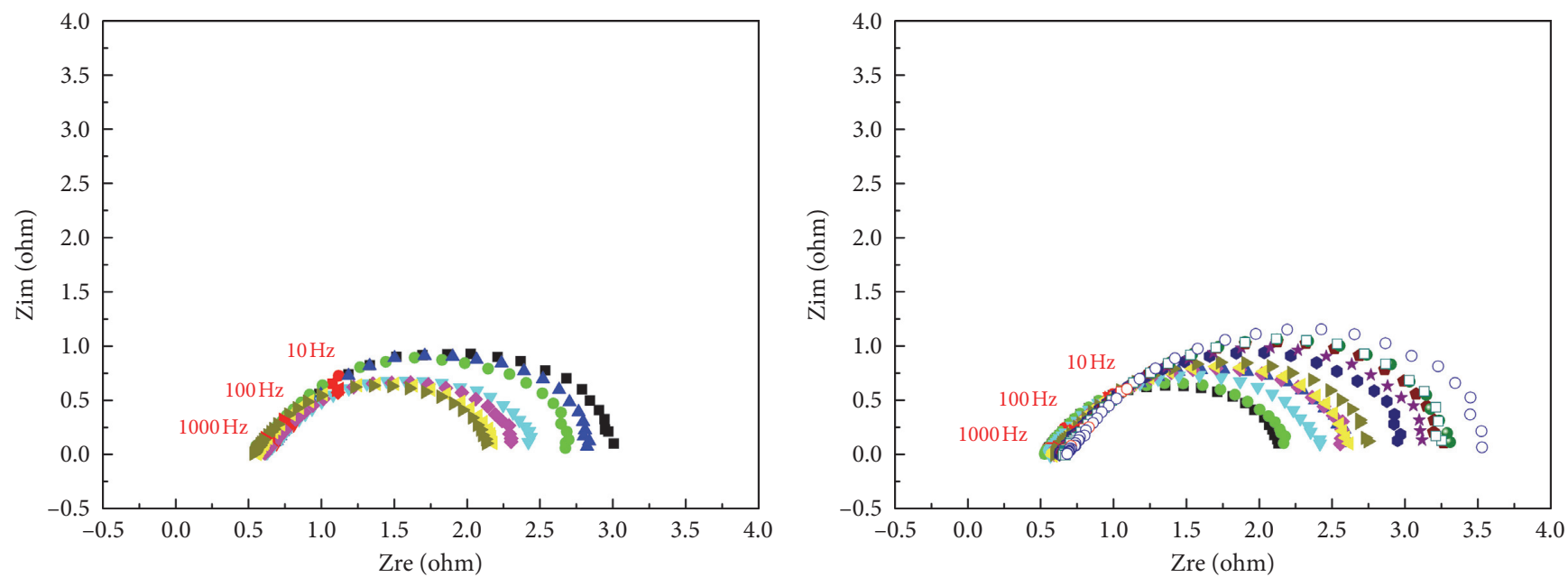

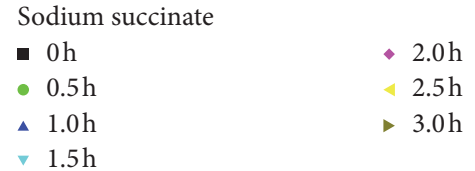

(a)

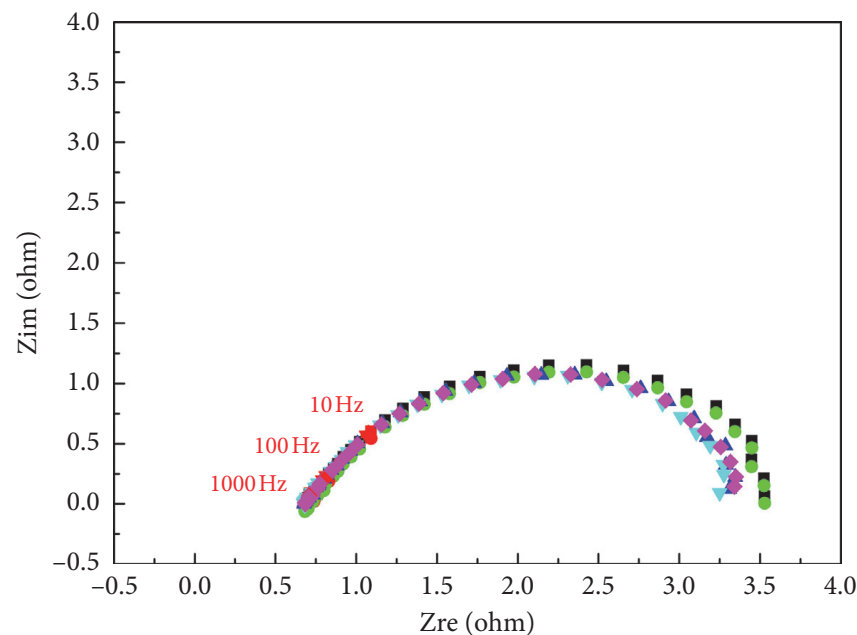

Sodium succinate

$\begin{array}{ll}\text { - } 9.0 \mathrm{~h} & \nabla 10.5 \mathrm{~h} \\ \text { - } 9.5 \mathrm{~h} & -11.0 \mathrm{~h} \\ \text { × } 10.0 \mathrm{~h} & \end{array}$

(c)

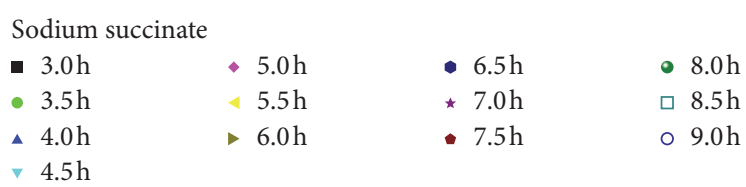

(b)

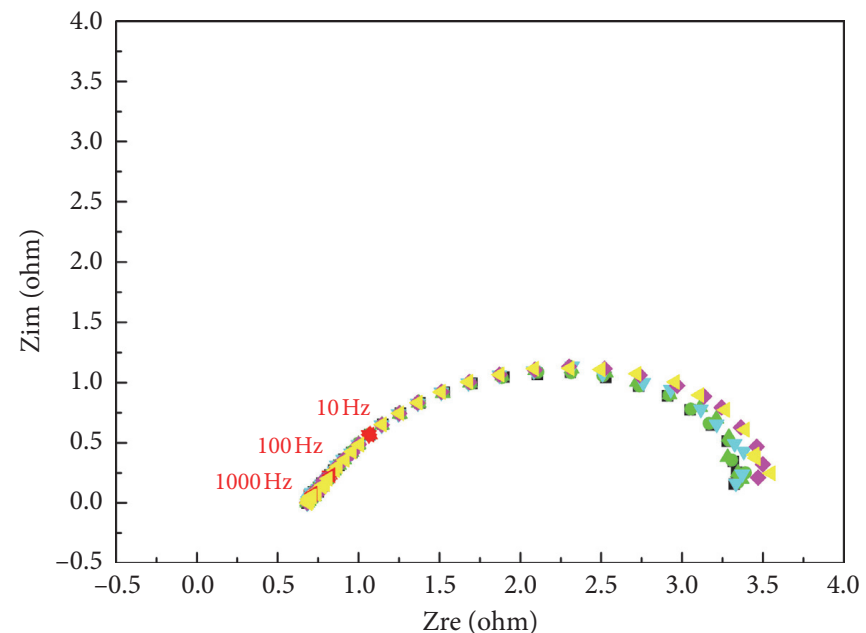

Sodium succinate

$\begin{array}{ll}\text { - } 11.5 \mathrm{~h} & \nabla 13.0 \mathrm{~h} \\ -12.0 \mathrm{~h} & \checkmark 13.5 \mathrm{~h} \\ \Delta 12.5 \mathrm{~h} & 414.0 \mathrm{~h}\end{array}$

(d)

Figure 6: Nyquist diagrams at different times under the condition of adding sodium succinate. (a) $0-3.0 \mathrm{~h}$. (b) $3.0 \mathrm{~h}-9.0 \mathrm{~h}$. (c) $9.0 \mathrm{~h}-11.0 \mathrm{~h}$. (d) $11.5 \mathrm{~h}-14.0 \mathrm{~h}$.

3.3.2. Addition of Sodium Succinate. According to Figure 6(a), the capacitance arc decreases due to the dissolution of the oxide film. However, the time for decreasing the capacitance arc is significantly longer than that without inhibitor, which indicates that sodium succinate effectively slows down the dissolution rate of the oxide film and the pitting corrosion, thereby delaying the crack initiation time. Figure 6(b) shows that the capacitance arc starts to increases at $3 \mathrm{~h}$, indicating that cracks on the surface of metal begin to appear at $3 \mathrm{~h}$. The capacitance arc is higher than the condition of without corrosion inhibitor. Figure 6(c) shows a slight decrease in the capacitance arc between 9 and $11 \mathrm{~h}$, which indicates that the degree of increase in capacitance arc caused by crack initiation and metal repassivation is lower than the decrease in capacitance arc caused by metal dissolution. Therefore, sodium succinate is more inclined to inhibit crack initiation at this stage; Figure 6(d) shows that between 11.5 and $14.0 \mathrm{~h}$, the variation trend of capacitance arc becomes gentle during the crack propagation stage. Sodium succinate can help suppress crack propagation and slow down the metal corrosion during this stage. 

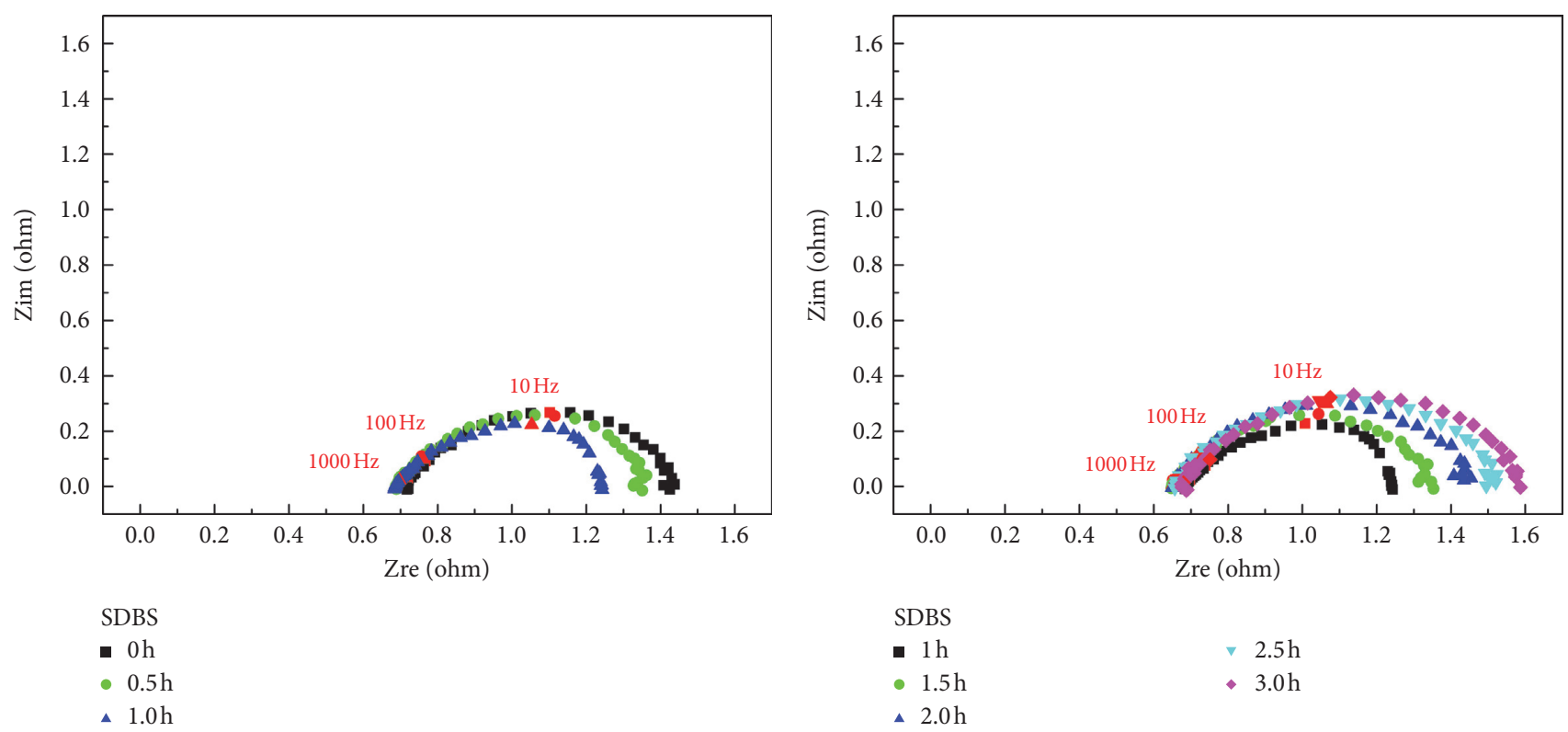

(a)

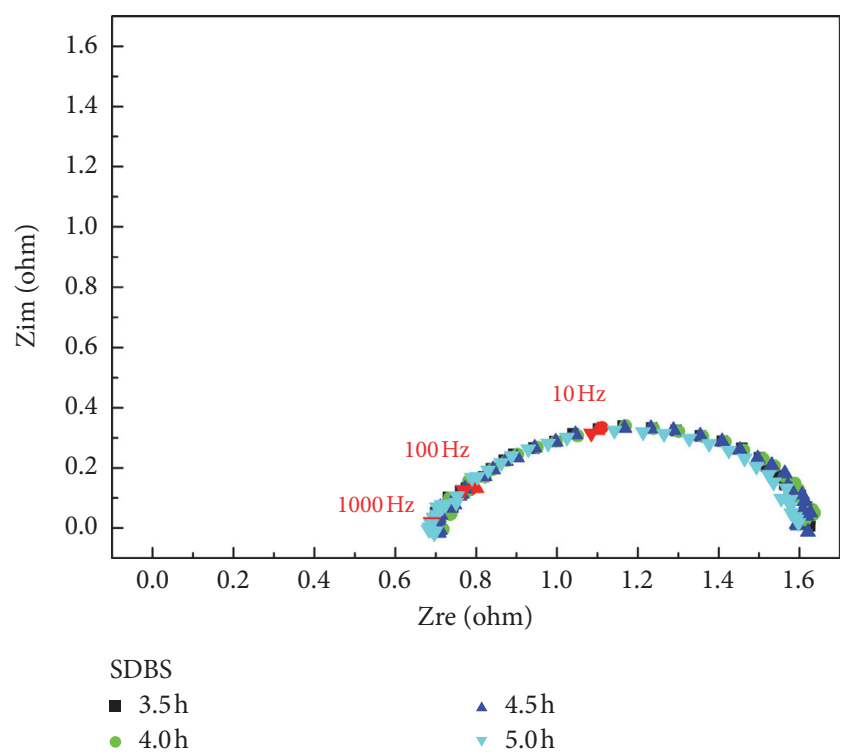

(c)

(b)

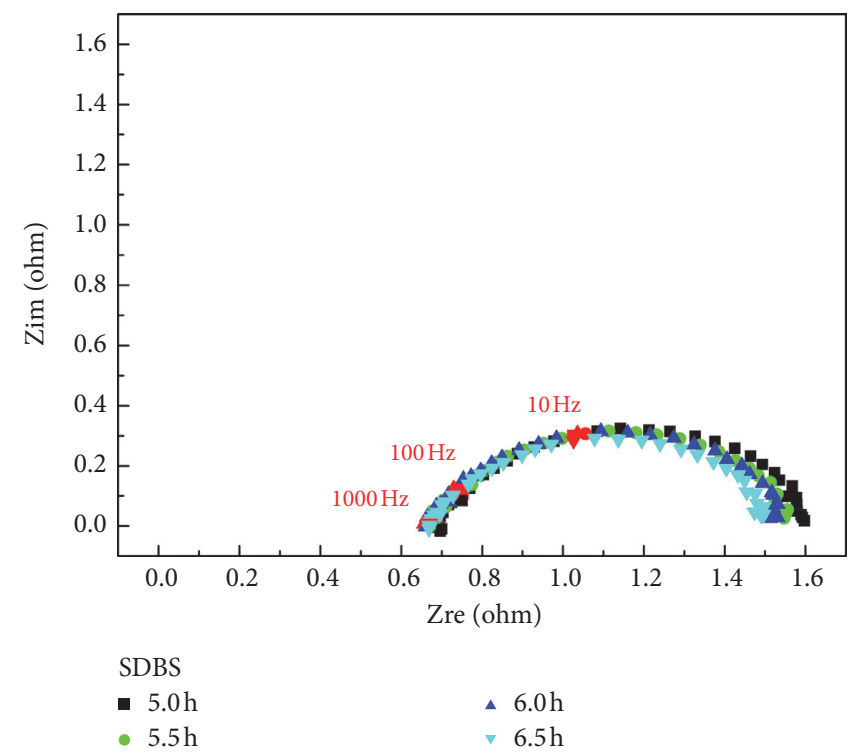

(d)

FIgURe 7: Nyquist diagrams at different times under the condition of adding SDBS: (a) $0-3.0 \mathrm{~h}$. (b) $3.0 \mathrm{~h}-9.0 \mathrm{~h}$. (c) $9.0 \mathrm{~h}-11.0 \mathrm{~h}$. (d) $11.5 \mathrm{~h}-14.0 \mathrm{~h}$.

3.3.3. Addition of SDBS. According to Figure 7(a), the capacitance arc decreases with time, indicating that the oxide film on the metal surface is dissolved under the action of the acid solution. Figure 7(b) shows that between 1.0 and $3.0 \mathrm{~h}$, the capacitance arc increases with time, indicating that cracks on the surface of the metal begin to appear at $1 \mathrm{~h}$. Figure $7(\mathrm{c})$ shows that the capacitance arc reaches a dynamic equilibrium between 3.5 and $5.0 \mathrm{~h}$. As shown in Figure $7(\mathrm{~d})$ as between 5.0 and $6.5 \mathrm{~h}$, the capacitance arc decreases with time, indicating that the increasing trend of the capacitance arc caused by the crack propagation is less than that of the metal dissolution and delayed the crack propagation time.
3.3.4. Addition of New Corrosion Inhibitor. Figure 8(a) shows that between 0 and $1 \mathrm{~h}$, capacitance decreases due to dissolution and pitting of the oxide film. Figure $8(\mathrm{~b})$ shows that the capacitance arc starts to increase at $1 \mathrm{~h}$, indicating that cracks on the surface of metal begin to appear at $1 \mathrm{~h}$. The capacitance arc is slightly higher than the condition of without corrosion inhibitor. Figure 8(c) shows the dynamic balance in the capacitance arc between 2.5 and $4.5 \mathrm{~h}$, which indicates that the degree of increase in capacitance arc caused by crack initiation and metal repassivation and the decrease in capacitance arc caused by metal dissolution are similar. Figure $8(\mathrm{~d})$ shows that between 5 and $7 \mathrm{~h}$, the variation trend of capacitance arc becomes gentle during the 


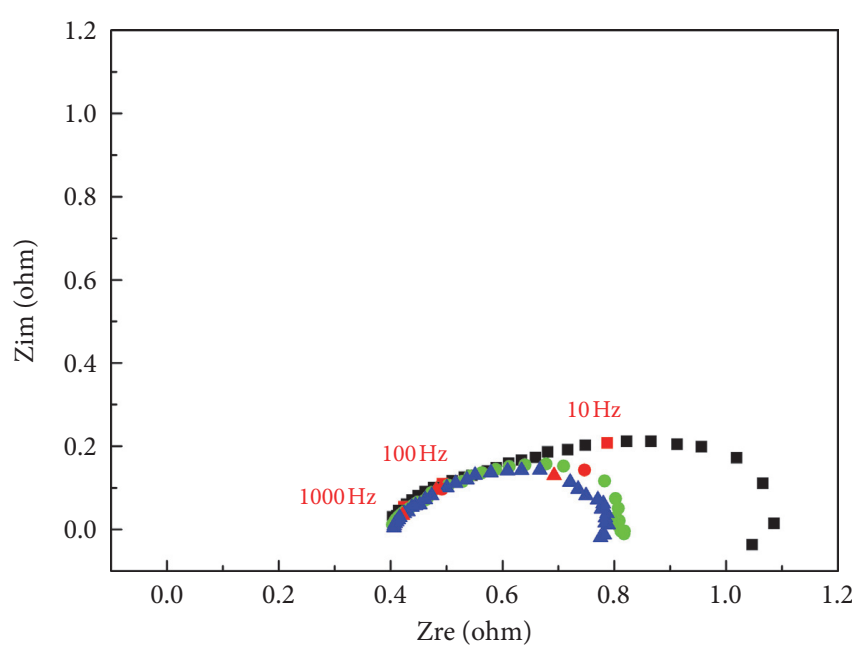

New corrosion inhibitor

- $0 \mathrm{~h}$

- $0.5 \mathrm{~h}$

^ $1.0 \mathrm{~h}$

(a)

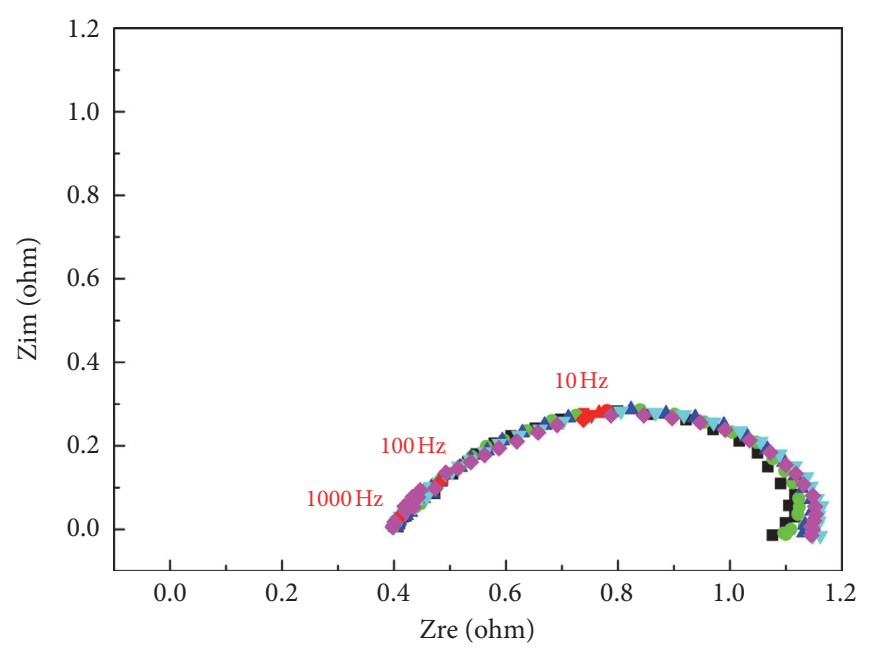

New corrosion inhibitor

$\begin{array}{ll}\text { - } 2.5 \mathrm{~h} & \nabla 4.0 \mathrm{~h} \\ -3.0 \mathrm{~h} & -4.5 \mathrm{~h} \\ & \end{array}$

(c)

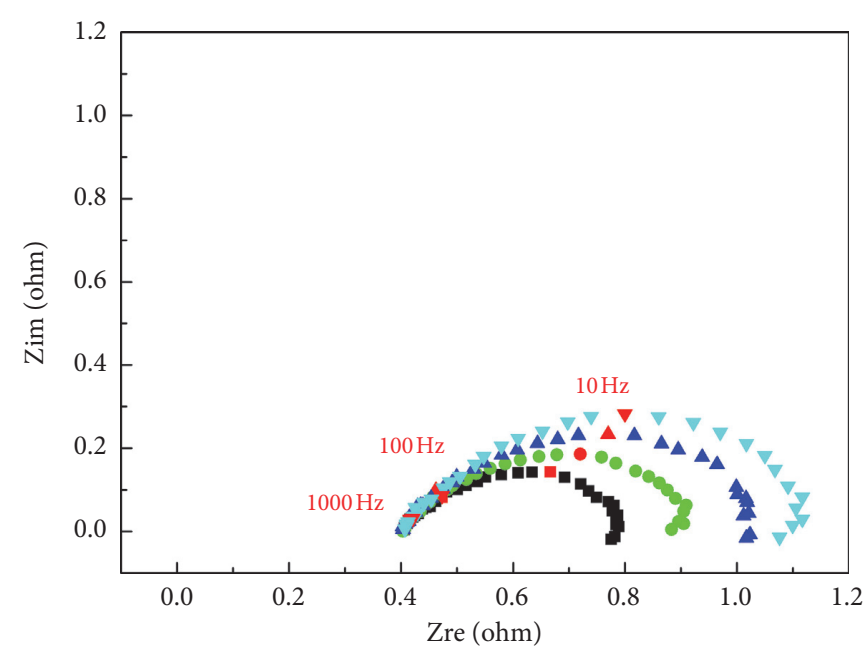

New corrosion inhibitor
- $1.0 \mathrm{~h}$
- $2.0 \mathrm{~h}$
- $1.5 \mathrm{~h}$
$\checkmark 2.5 \mathrm{~h}$

(b)

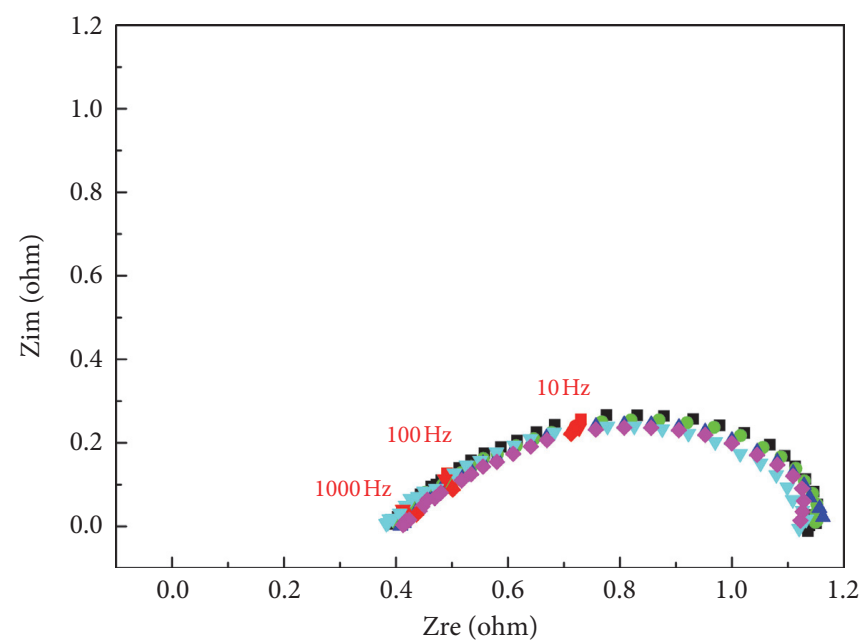

New corrosion inhibitor
- $5.0 \mathrm{~h}$
v $6.5 \mathrm{~h}$
- $5.5 \mathrm{~h}$
- 7.0h
^ $6.0 \mathrm{~h}$

(d)

Figure 8: Nyquist diagrams at different times under the condition of adding new corrosion inhibitor: (a) $0-1.0 \mathrm{~h}$. (b) $1.0 \mathrm{~h}-2.5 \mathrm{~h}$. (c) $2.5 \mathrm{~h}-4.5 \mathrm{~h}$. (d) $5.0 \mathrm{~h}-7.0 \mathrm{~h}$.

crack propagation stage. New corrosion inhibitor is added mainly to slow down the metal corrosion during this stage.

\subsection{Effect of Corrosion Inhibitor on Crack Initiation and} Propagation in Stress Corrosion Process by Phase Shift Method. The experimental group with the addition of a new corrosion inhibitor was selected to plot the phase shift-frequency curve at the moment of crack initiation and propagation. According to Figure 9, we can predict the change of crack in 7A04 aluminum alloy during the SSRT process by observing the change of phase shift in the $1-100 \mathrm{~Hz}$ frequency range, because the phase shift in this interval is the most significant. The phase shift in the lower frequency range is subject to large fluctuations, and errors are considered for long-term measurements. Therefore, choose to supplement the phase shift at $1000 \mathrm{~Hz}$ to improve the credibility of the experimental data.

The load-time and phase shift-time curve are shown in Figure 10, in the condition of without the addition of corrosion inhibitors and three types of corrosion inhibitors.

It can be seen from Figure 10(a) that under the condition of without corrosion inhibitor, the peak value of the three frequencies appeared at about $1 \mathrm{~h}$. It is inferred that at the 


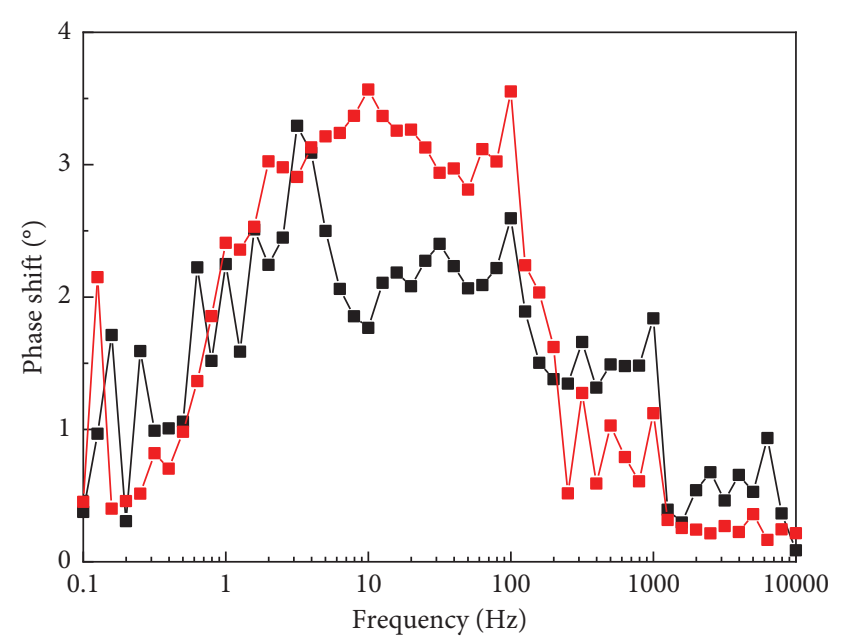

New corrosion inhibitor

$-\mathbf{-}-1 \mathrm{~h}$

$-5 \mathrm{~h}$

Figure 9: Bode plot with the phase shift in function of the logarithm of the frequency.

crack initiation at this time and at about $3.5 \mathrm{~h}$, the three frequencies showed obvious peaks. It is inferred that there is crack propagation at this time. Figure 10(b) infers that the crack initiation began at about $1 \mathrm{~h}$ after the addition of $0.5 \mathrm{~g} / \mathrm{L}$ SDBS and the crack propagation at $4.5 \mathrm{~h}$. Figure 10(c) infers that the crack initiation began at about $3 \mathrm{~h}$ after the addition of $7.5 \mathrm{~g} / \mathrm{L}$ sodium succinate and the crack propagation at $8 \mathrm{~h}$. Figure $10(\mathrm{~d})$ infers that the crack initiation began at about $1 \mathrm{~h}$ after the addition of $0.6 \mathrm{~g} / \mathrm{L}$ new corrosion inhibitor and the crack propagation at $5 \mathrm{~h}$.

The results of the phase shift method show that the new corrosion inhibitor and SDBS cannot effectively inhibit the crack initiation in the SSRT process of aluminum alloy, but sodium succinate can delay the crack initiation time backward for 2 hours. Three types of corrosion inhibitors have certain inhibition effect on the crack propagation time. The inhibition effect is as follows: $\operatorname{SBDS}<$ new corrosion inhibitor $<$ sodium succinate. Sodium succinate is the most effective in inhibiting crack propagation.

Based on the combination of EIS and phase shift, it is inferred that the possible reasons for this result are as follows.

At the crack initiation stage, the capacitance arc increases obviously after adding sodium succinate. Therefore, sodium succinate can effectively improve the corrosion resistance of aluminum alloy at this stage. In the early stages of SSRT, the dissolution of the metal oxide film was slowed down, the formation of surface defects such as pitting pits was reduced, and the possibility of occurrence of intergranular corrosion at these defects and the formation of stress concentration leading to ductile failure [18] was reduced. Thus, the crack initiation is restrained and the crack initiation time is delayed backward. In the same way, for the new corrosion inhibitor and SDBs, it can be found that in the initial stage of SSRT, the capacitance arc is not obviously increased, and the effect of the earlier stage on slowing the corrosion of metal is not remarkable, and the formation of pitting pits is not effectively inhibited, so the initiation of cracks cannot be effectively inhibited. The crack initiation time is basically the same as that without corrosion inhibitor.

At the stage of crack propagation, the variation trend of capacitance arc of sodium succinate is gentle, which indicates that sodium succinate still effectively inhibits the corrosion of metal in the stage of crack propagation, resulting in the decrease of intergranular cracking rate [18] and the inhibition of crack propagation, and the time of crack propagation is delayed. The variation trend of SDBS is basically the same as that without corrosion inhibitor, and the capacitance arc is slightly increased, which indicates that SDBS mainly attenuates metal corrosion to suppress stress corrosion during the SSRT process. The capacitance arc of the new corrosion inhibitor changes slowly at the stage of crack propagation, indicating that the new corrosion inhibitor still has a good effect on inhibiting metal corrosion at the stage of crack propagation.

In addition, the phase shift method combined with loadtime curve shows that the crack initiation and propagation time of SDBS and the new corrosion inhibitor are in the linear elastic deformation stage of aluminum alloy during the SSRT process. The position of crack initiation time in the load-time curve after adding two kinds of corrosion inhibitors is approximately the same as that of the condition of without corrosion inhibitor. The position of crack propagation time under load-time curve moves backward compared with that without the corrosion inhibitor. Compared with SDBS and new corrosion inhibitor, the crack initiation and propagation time after adding sodium succinate was delayed backward, and the crack propagation time appeared in the strain hardening stage. It can be concluded that SDBS and new corrosion inhibitor mainly inhibit the crack initiation and obvious propagation in the linear elastic stage of aluminum alloy in the SSRT process, while sodium succinate can inhibit the crack propagation in the strain-hardening stage. In addition, Figure 8 also shows the change of stress corrosion sensitivity of aluminum alloy during SSRT process can be explained by adding three kinds of corrosion inhibitors. The relation of stress corrosion sensitivity is as follows: SDBS $<$ new corrosion inhibitor $<$ sodium succinate.

3.5. Validation of Experimental Data by Kramers-Kronig Transformation. Using equivalent circuit [19] software, the imaginary part of the impedance of a setup of EIS data is calculated with the experimental values of the real part of the impedance. Then, the KKT data and experimental data are drawn together. If both graphs are similar, it is assumed that the experimental data are of good quality, i.e., the SCC system has not remarkably changed in measurement. Under the condition of without corrosion inhibitor and three kinds of corrosion inhibitor, the reliability of the data was verified by KKT at the time of crack initiation and propagation. The results are as follows.

Figure 11 shows the comparison between the experimental and calculated values at the time of crack initiation 


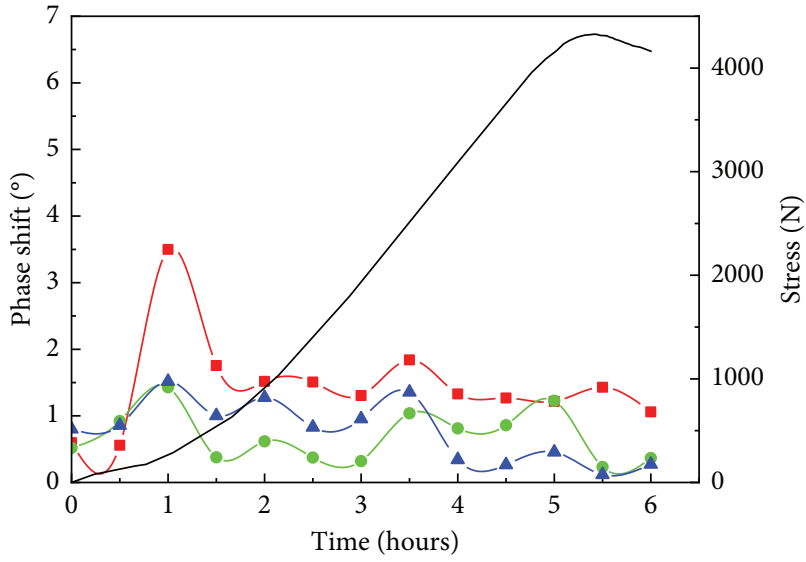

Without corrosion inhibitor $\begin{array}{ll}\rightarrow-10 \mathrm{~Hz} & -\triangle 1000 \mathrm{~Hz} \\ \rightarrow-100 \mathrm{~Hz} & - \text { Stress }\end{array}$

(a)

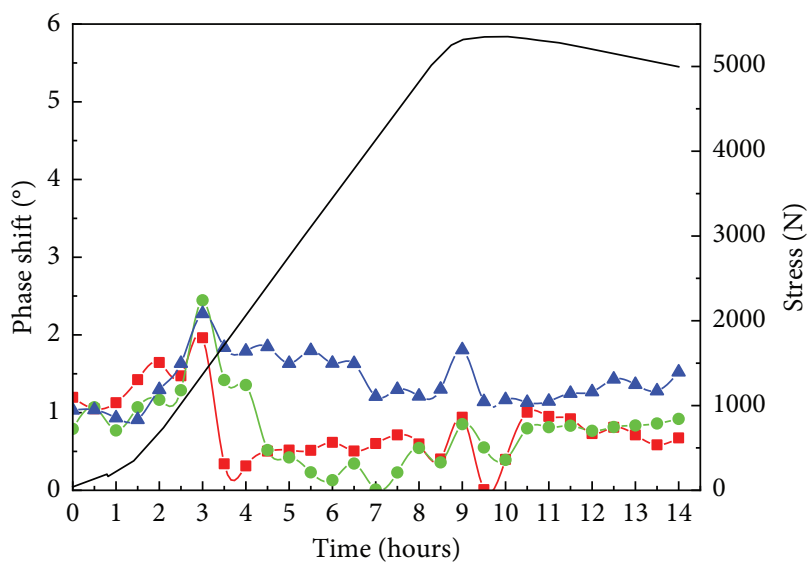

$\begin{array}{ll}\text { Sodium succinate } & \\ --10 \mathrm{~Hz} & -\_1000 \mathrm{~Hz} \\ --100 \mathrm{~Hz} & - \text { Stress }\end{array}$

(c)

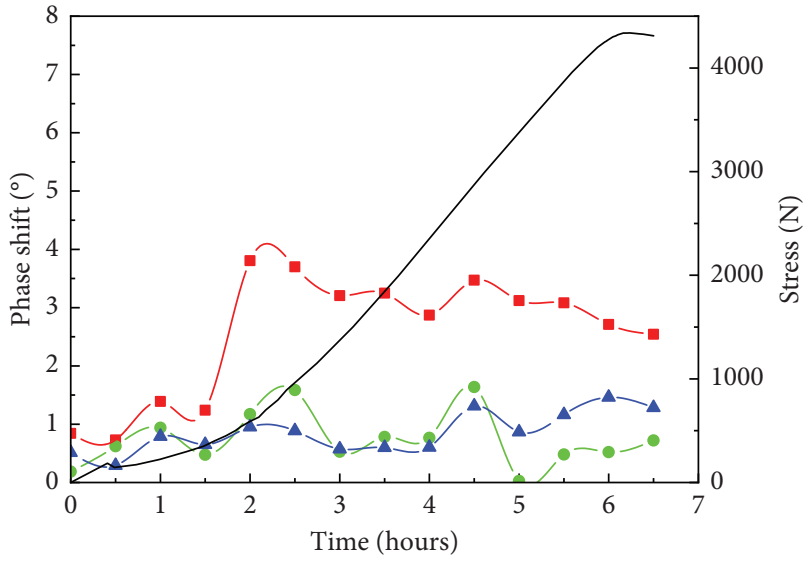

SDBS

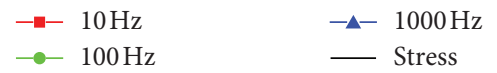

(b)

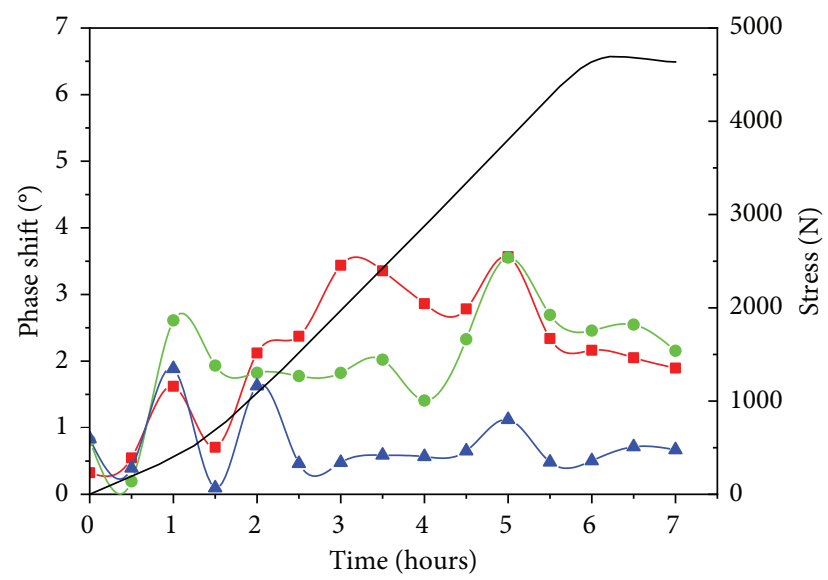

$\begin{array}{ll}\text { New corrosion inhibitor } & \\ --10 \mathrm{~Hz} & -\Delta-1000 \mathrm{~Hz} \\ --100 \mathrm{~Hz} & - \text { Stress }\end{array}$

(d)

FIGURE 10: Images of the phase shift-time with different inhibitors: (a) without inhibitor. (b) $0.5 \mathrm{~g} / \mathrm{L}$ SDBS. (c) $7.5 \mathrm{~g} / \mathrm{L}$ sodium succinate. (d) $0.6 \mathrm{~g} / \mathrm{L}$ new corrosion inhibitor.

and propagation under different conditions. It can be seen from the diagram that the calculated values and the experimental values are very close, and the large difference in individual data can be considered to be caused by the unreliable data at this frequency. Thus, the accuracy of experimental data can be confirmed.

3.6. Fitting Analysis of Electrochemical Impedance Spectroscopy. The EIS can be fitted by Zview software. The equivalent circuit [20] is shown in Figure 12.

The equivalent circuit is composed of the following components: $R_{\mathrm{s}}$ is the solution resistance $\left(\Omega \cdot \mathrm{cm}^{2}\right) ; Z_{\text {crack }}$ $\left(\Omega \cdot \mathrm{cm}^{2}\right)$ represents the total crack impedance [20]; $R_{\mathrm{ct}}$ is the charge transfer resistance $\left(\Omega \mathrm{cm}^{2}\right)$, which is controlled by the electrochemical reaction kinetics. The capacitance arc is depressed semicircle, which indicates that the electrode reaction has dispersion effect, so the constant phase angle element (CPE), which represents the double layer capacitance, is added to fit it. This caused the frequency response characteristics of the electric double layer capacitor to deviate from the pure capacitance [21], presumably caused by insufficient smooth surface of the electrode. CPE is composed of parameter $Y_{0}\left(\Omega^{-1} \cdot \mathrm{cm}^{-2} \cdot \mathrm{s}^{-n}\right)$ and $n$, which represent the CPE constant and the CPE index, respectively. The trend of $Y_{0}$ is opposite to the polarization resistance $R_{\mathrm{ct}}$. Table 1 shows the fitting data obtained under different conditions (the values in the table represent their range of change in SSRT).

\subsection{Verification of the Combination of Phase Shift and EIS}

3.7.1. SEM and EDS Verification. In order to study the effect of corrosion inhibitor on crack initiation and propagation in the SSRT process of 7A04 aluminum alloy and to verify the 

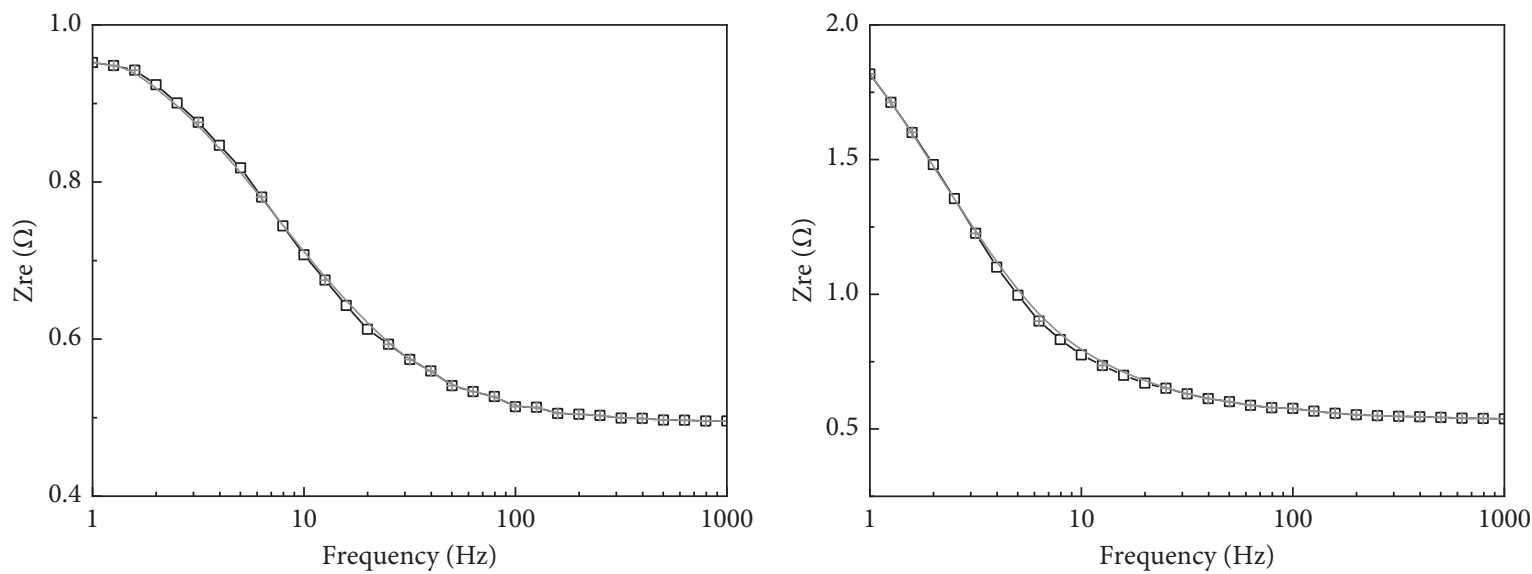

Without corrosion inhibitor

$\rightarrow-$ Zre experimental

Sodium succinate

$\rightarrow \square-$ Zre experimental

+ Zre KKT

(a)
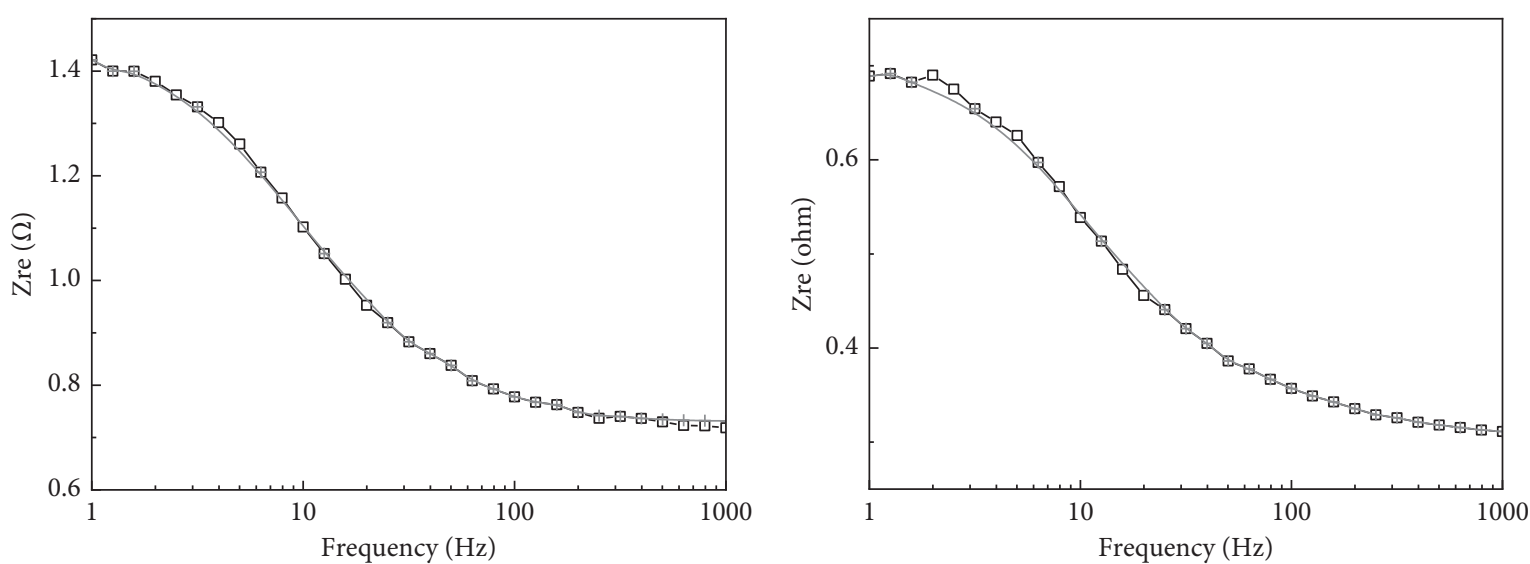

SDBS

$\rightarrow-Z^{\prime}$ experimental

$+\mathrm{Z}^{\prime} \mathrm{KKT}$

New corrosion inhibitor

- - Zre experimental

-+ Zre KKT

(c)

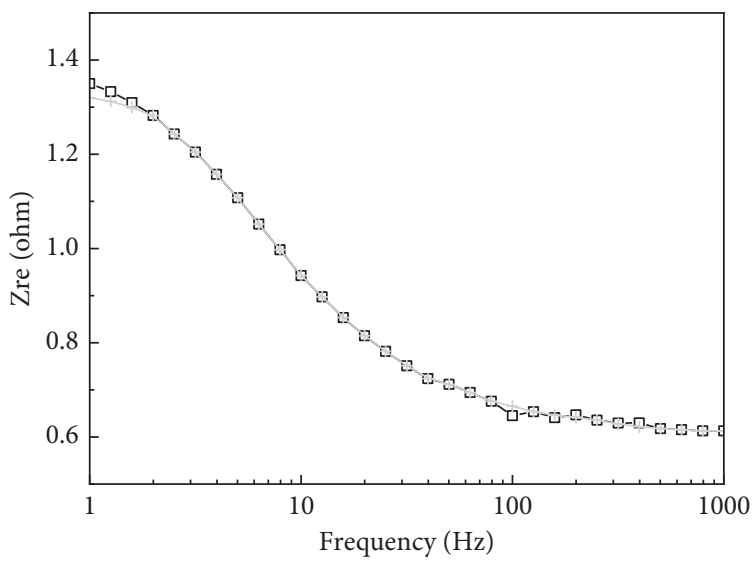

Without inhibitor

$\neg-$ Zre experimental

+ Zre KKT

(d)

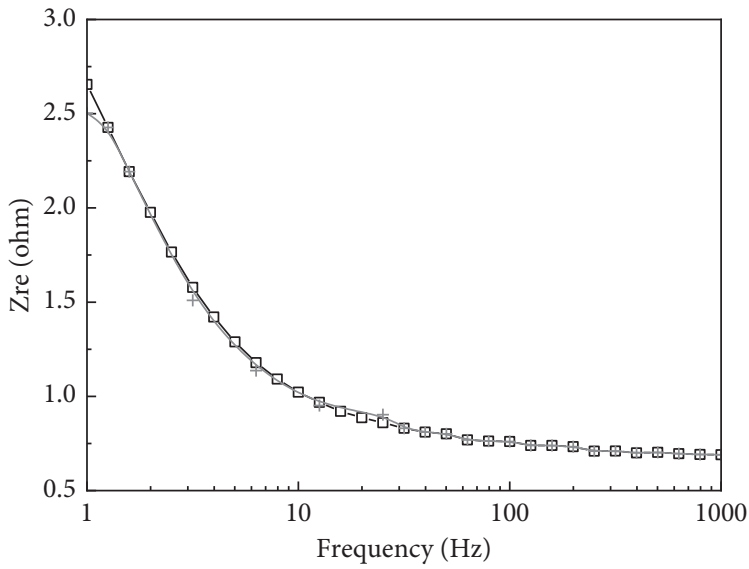

Sodium succinate

- - Zre experimental

- - Zre KKT

(e)

Figure 11: Continued. 


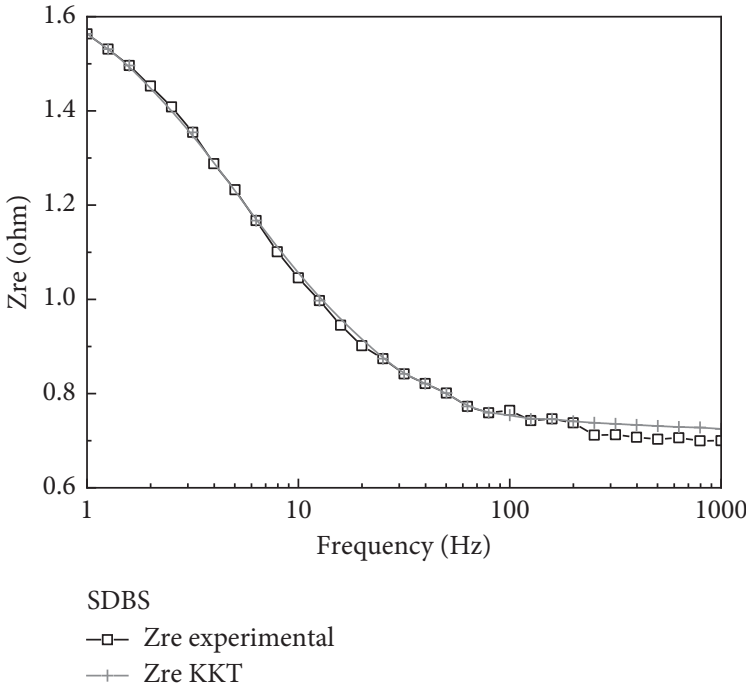

(g)

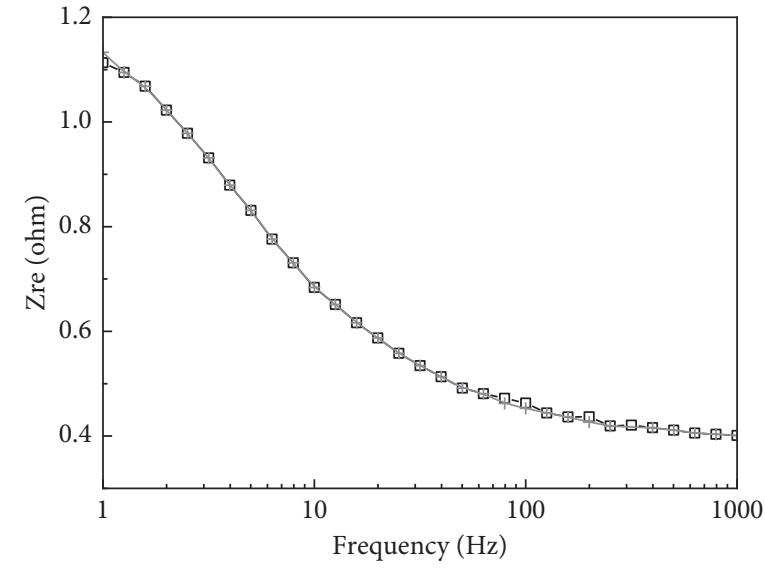

New inhibitor

- - Zre experimental $\rightarrow$ Zre KKT

(h)

FIgURE 11: Comparison of experimental and KKT values of Zreal. Creak initiation: (a) without inhibitor. (b) Sodium succinatec. (c) SDBS. (d) New corrosion inhibitor. Creak propagation: (e) without inhibitor. (f) Sodium succinate. (g) SDBS. (h) New corrosion inhibitor.

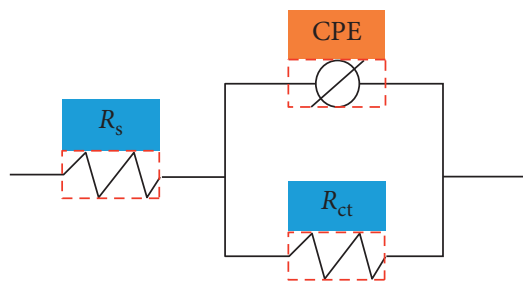

(a)

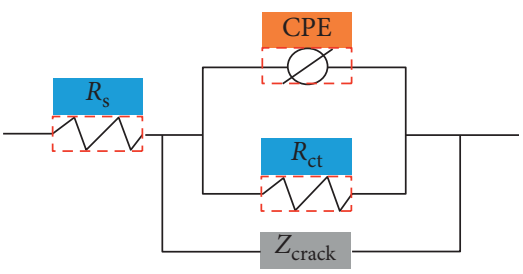

(b)

FIGURE 12: Fitting circuit of nyquist diagram: (a) equivalent circuit before cracking; (b) equivalent circuit after cracking.

TABLE 1: Fitting parameters of equivalent circuit.

\begin{tabular}{|c|c|c|c|c|c|}
\hline & $R_{\mathrm{s}}\left(\Omega \cdot \mathrm{cm}^{2}\right)$ & $R_{\mathrm{ct}}\left(\Omega \cdot \mathrm{cm}^{2}\right)$ & $Y_{0}\left(10^{-4} \Omega^{-1} \cdot \mathrm{cm}^{-2} \cdot \mathrm{s}^{-1}\right)$ & $n_{\mathrm{dl}}$ & $Z_{\text {CRACK }}\left(\Omega \cdot \mathrm{cm}^{2}\right)$ \\
\hline Blank & $0.71-0.82$ & $0.19-0.27$ & $0.81-2.13$ & $0.87-0.93$ & $3284-3416$ \\
\hline Sodium succinate & $0.81-0.94$ & $0.78-1.41$ & $0.22-0.42$ & $0.78-0.92$ & $5150-5752$ \\
\hline New corrosion inhibitor & $0.69-0.79$ & $0.21-0.38$ & $0.8-2.31$ & $0.76-0.95$ & $4095-4271$ \\
\hline SDBS & $0.73-0.80$ & $0.23-0.47$ & $0.72-2.36$ & $0.75-0.94$ & $3386-3774$ \\
\hline
\end{tabular}

feasibility of combining EIS with phase shift, the new corrosion inhibitor was selected to sample at the time of crack initiation and propagation and remove the surface corrosion products, and then the surface of the sample was observed by SEM and EDS.

Figures 13(a)-13(c) are SEM pictures of the crack initiation and propagation in the SSRT process with the addition of a new corrosion inhibitor. (a) SEM picture, and there is no crack and corrosion on the surface. (b) SEM picture of adding new corrosion inhibitor at the crack initiation time, and it can be seen that the surface crack of aluminum alloy begins to germinate, and there is no obvious precipitate near the crack. (c) SEM picture of the crack propagation time when a new corrosion inhibitor is added, and it can be seen that there are many large and deep cracks on the surface of the metal, which indicates that the crack begins to propagate.
Figure 13(d) shows the SEM and EDS pictures of the crack initiation time under the condition of a new corrosion inhibitor. The results show that the elements of $\mathrm{Al}$ and $\mathrm{Zn}$ appear in the energy spectrum, which is mainly composed of metal matrix. In addition, elements $\mathrm{C}$ and $\mathrm{O}$ have emerged, indicating that new corrosion inhibitors may exist on the metal surfaces.

Figure 13(e) shows the SEM and EDS pictures of the crack obvious propagation time under the condition of a new corrosion inhibitor. The results show that the elements of $\mathrm{Al}, \mathrm{Mg}$, and $\mathrm{Zn}$ appear in the energy spectrum, which is mainly composed of metal matrix. In addition, elements $\mathrm{C}$ and $\mathrm{O}$ also appeared and the contents of elements were higher than those at crack initiation. The results of SEM and EDS show that the phase shift method is feasible to predict the time of crack initiation and propagation. 


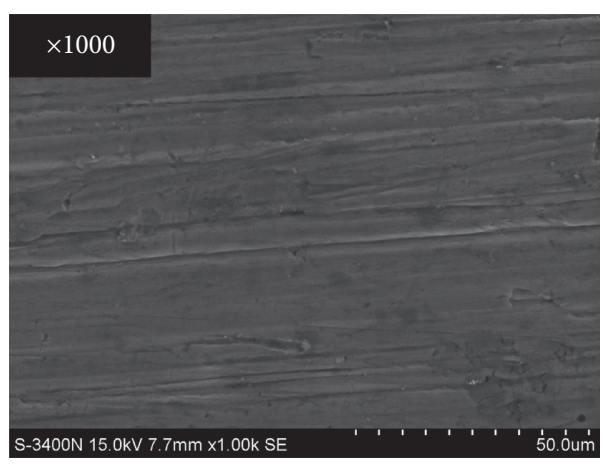

(a)

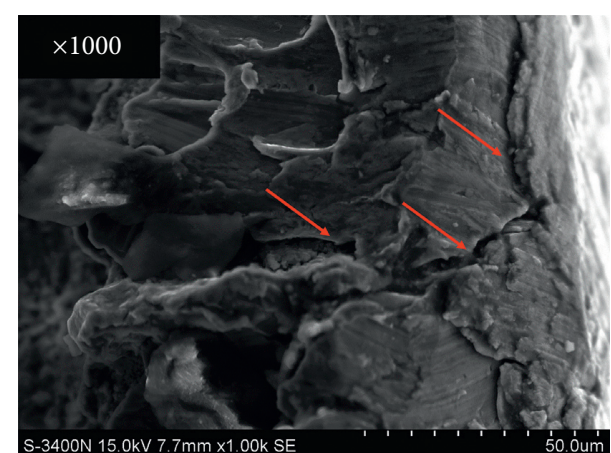

(b)

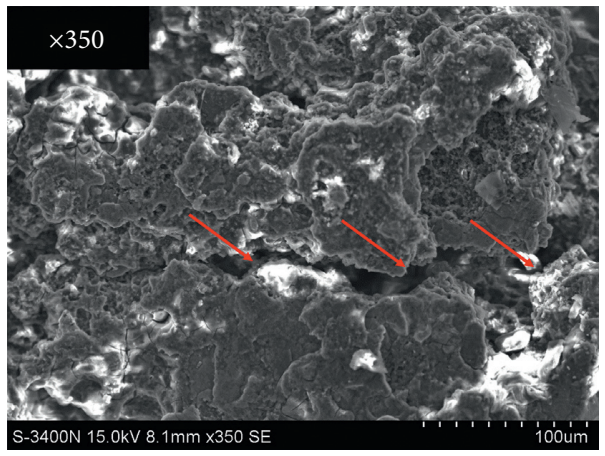

(c)
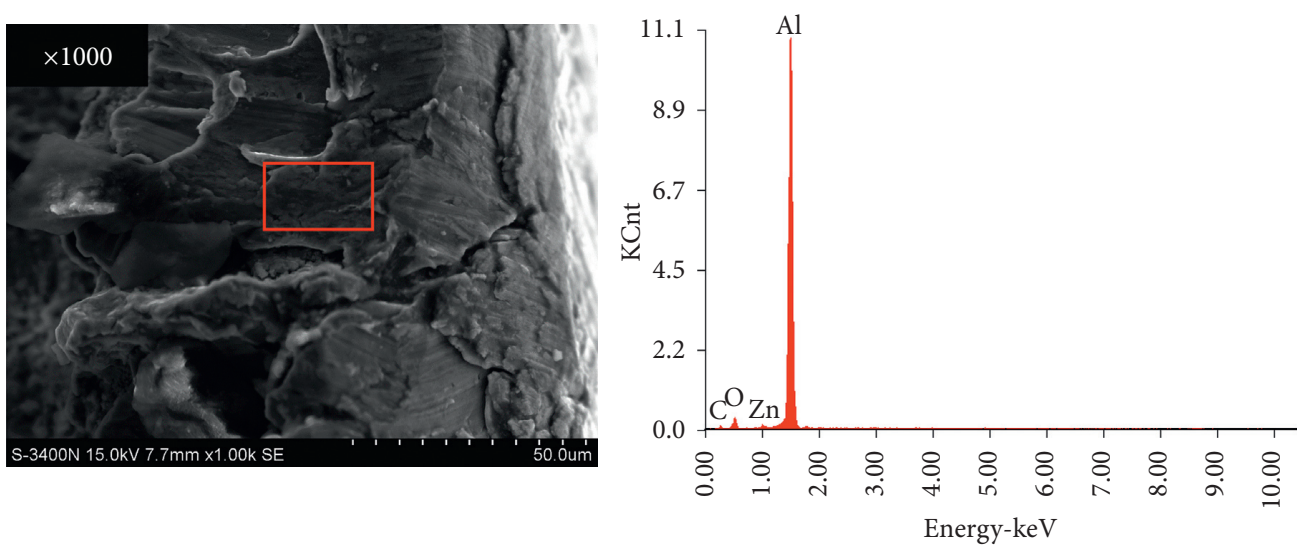

(d)
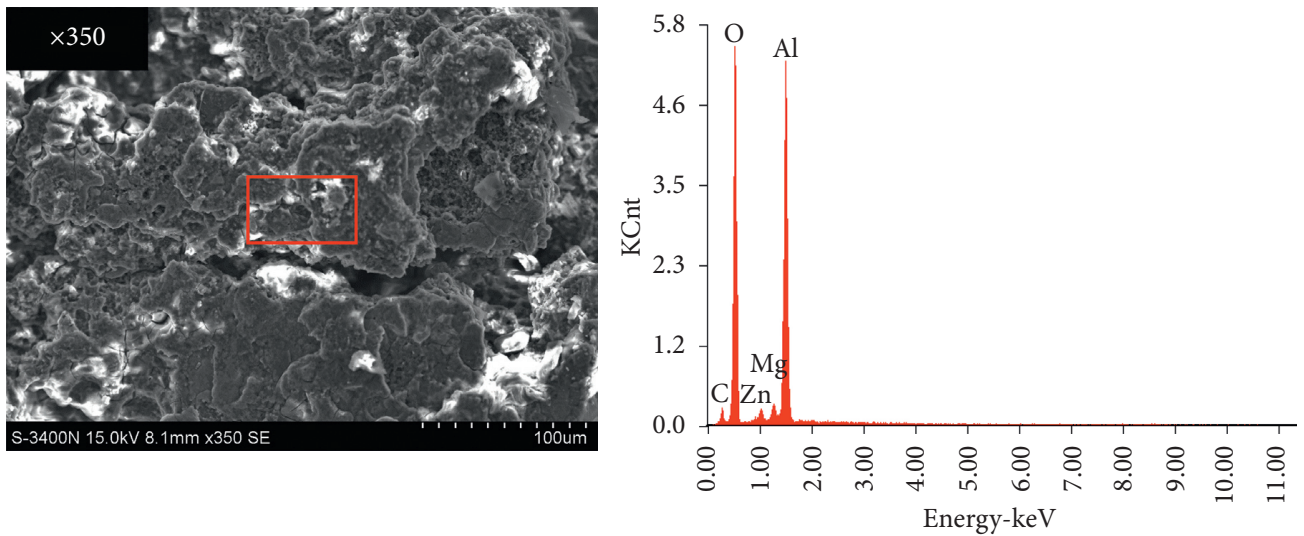

(e)

FIGURE 13: SEM and EDS images of crack initiation and obvious propagation time. SEM: (a) 7A04 aluminum alloys. New corrosion inhibitor at (b) crack initiation time and (c) crack propagation time. SEM and EDS images at (d) crack initiation time and (e) crack obvious propagation time. 


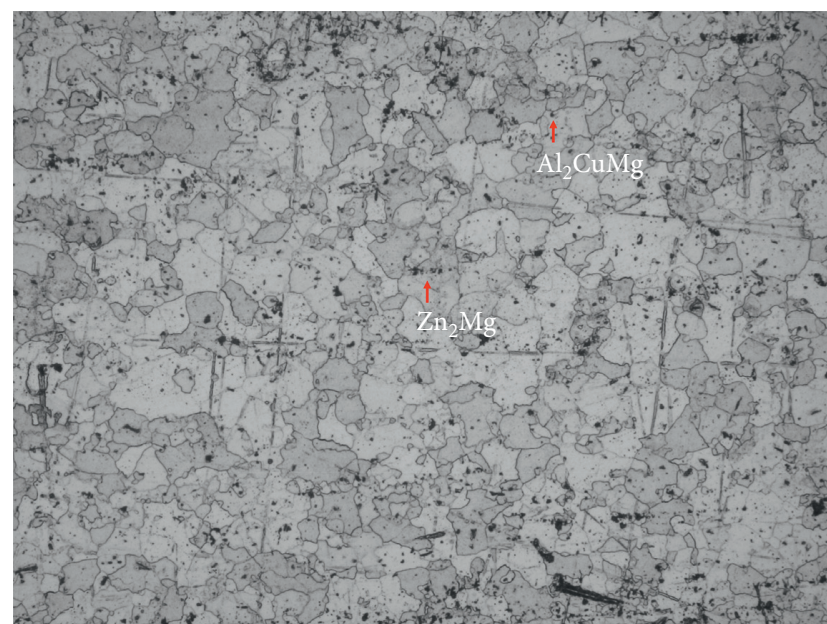

(a)

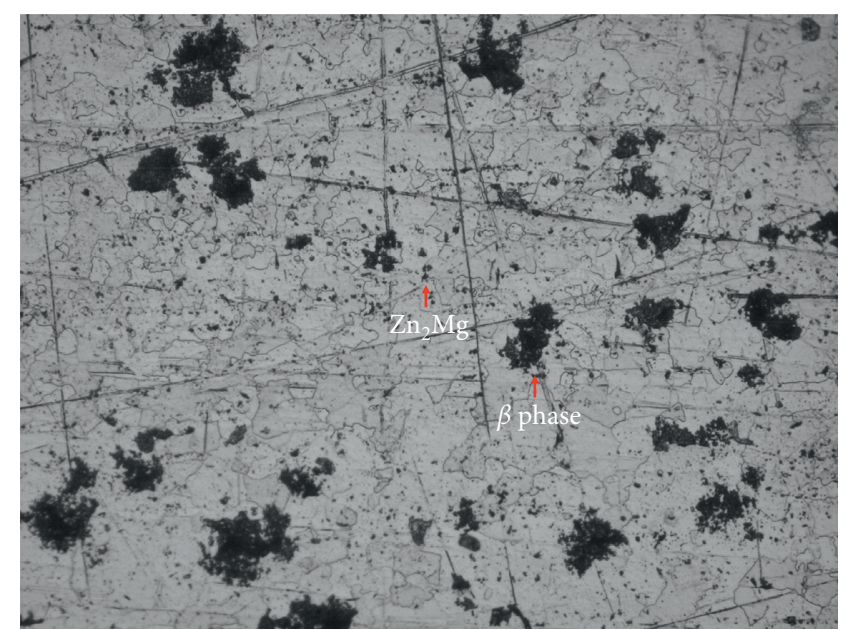

(b)

Figure 14: (a) Crack initiation. (b) Crack obvious propagation.

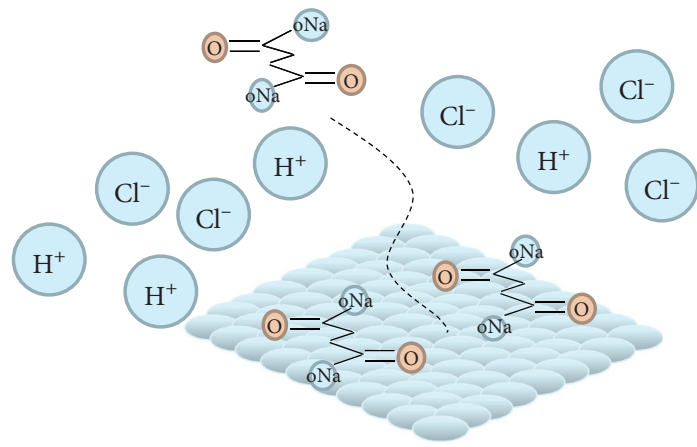

7A04 aluminum alloy<smiles>CCCOC(=O)C(=O)O</smiles>

FIGURE 15: Schematic diagram of the corrosion inhibition mechanism of sodium succinate.

3.7.2. Metallographic Verification. The metallography of 7A04 aluminum alloy is mainly composed of $\alpha-\mathrm{Al}, \mathrm{Zn}_{2} \mathrm{Mg}$, and $\mathrm{Al}_{2} \mathrm{CuMg}$ during crack initiation [22], while the metallography at crack propagation stage is mainly composed of $\alpha-\mathrm{Al}$ and $\mathrm{Zn}_{2} \mathrm{Mg}[23,24]$.

The sample was sampled at the time of crack initiation and propagation under the condition of adding a new corrosion inhibitor. The results were observed under the Zeiss microscope, and the results are shown in Figure 14. The results of the metallographic analysis show that there is $\mathrm{S}\left(\mathrm{Al}_{2} \mathrm{CuMg}\right)$ phase and $\mathrm{g}\left(\mathrm{Zn}_{2} \mathrm{Mg}\right)$ phase in $\alpha$ - $\mathrm{Al}$ solid solution at the time of crack initiation. At the time of crack propagation, phase $\mathrm{y}\left(\mathrm{Zn}_{2} \mathrm{Mg}\right)$ and $\mathrm{B}$ phase (Insoluble impurities) are distributed on $\alpha$ - $\mathrm{Al}$ solid solution.

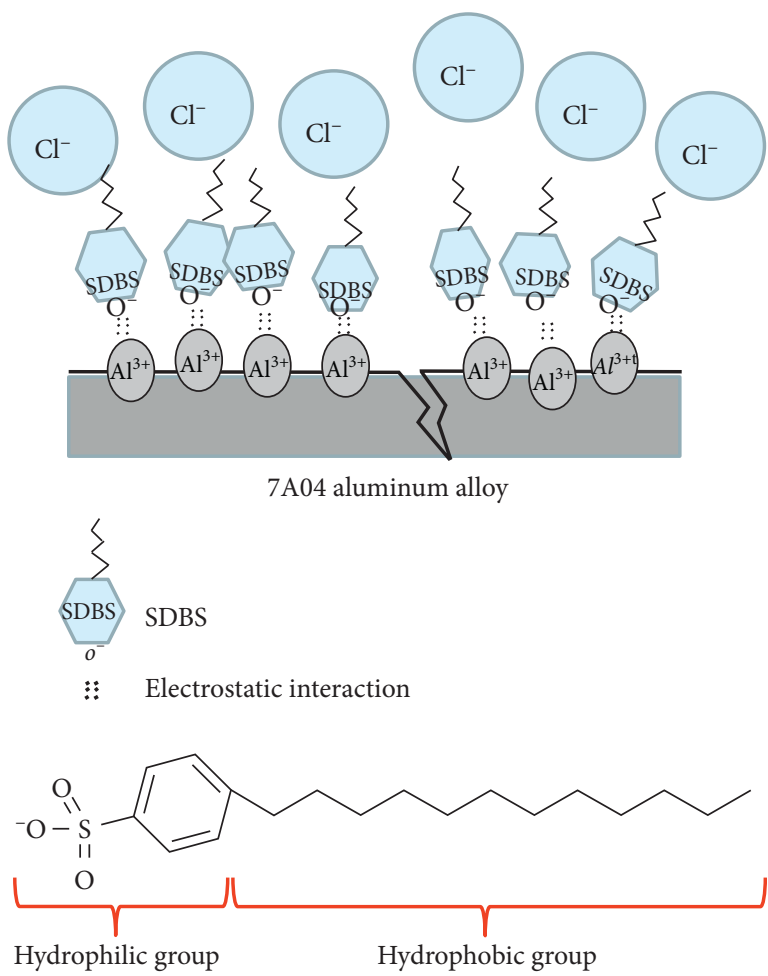

FIGURE 16: Schematic diagram of the corrosion inhibition mechanism of SDBS.

The results obtained by the metallographic test also prove that the phase shift method can be used to predict the time of crack initiation and propagation.

\section{Analysis of Corrosion Inhibition Mechanism}

4.1. Analysis of Corrosion Inhibition Mechanism of Sodium Succinate. Figure 15 shows the schematic diagram of the corrosion inhibition mechanism of sodium succinate. 


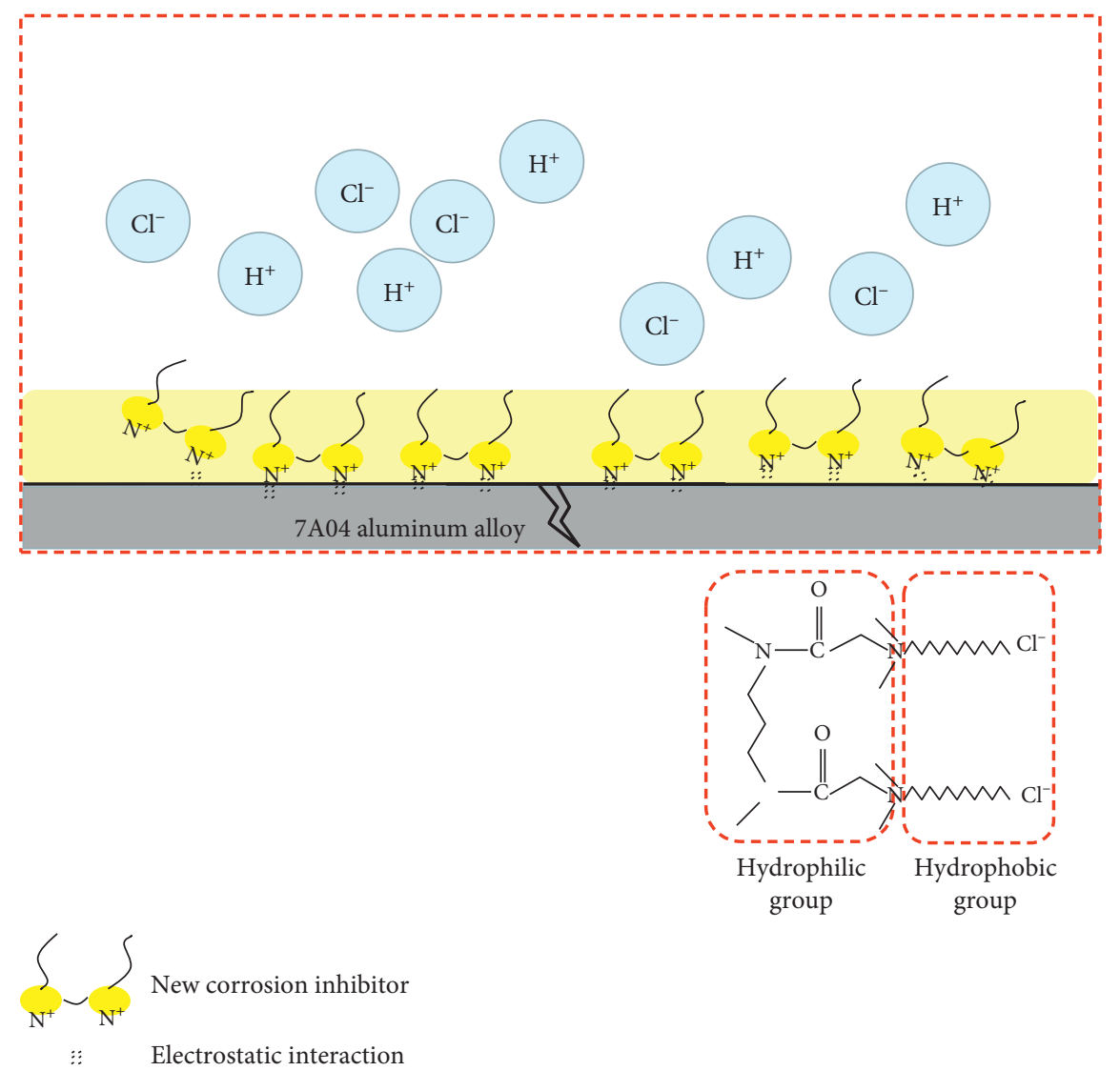

Figure 17: Schematic diagram of the corrosion inhibition mechanism of the new corrosion inhibitor.

Sodium succinate is an organic acid salt corrosion inhibitor, which functions as a mixed-type inhibitor [25]. The unbonded electrons in sodium succinate interact with the empty orbital of aluminum ion to form a coordination bond to adsorb on the surface of aluminum. At the stage of crack initiation, the aluminum alloy surface is covered with a film of sodium succinate, which retards the reduction of dissolved oxygen and effectively slows down the dissolution and pitting corrosion. However, with the increasing of stress, the molecular layer of sodium succinate on the surface is destroyed, and the metal surface is exposed to acid solution. Under the coupling of stress and corrosion, the crack initiation started.

At the stage of crack propagation, more metal surface is exposed to acid solution because of the crack propagation. Under the action of sodium succinate, the metal surface will be covered with a dense molecular layer. At first, the capacitance arc decreases due to metal dissolution and then the crack begins to propagate. At the beginning of the crack propagation, the crack propagation is restrained with the increasing of the area of the molecular layer of sodium succinate. Finally, the crack propagation and the continuous dissolution of the metal lead to the fracture of the metal. The change trend of capacitance arc shows that sodium succinate can effectively slow down the corrosion.

4.2. Analysis of Corrosion Inhibition Mechanism of SDBS. Figure 16 shows the schematic diagram of the corrosion inhibition mechanism of SDBS. SDBS is an organic corrosion inhibitor, which belongs to the cathodic corrosion inhibitor [26]. This can be attributed to the formation of a layer between the aluminum alloy surface and the SDBS through the electron pair donation of sulfur and oxygen atoms to the aluminum $[27,28]$. The addition of SDBS inhibited the active dissolution of the aluminum alloy and passivation was promoted [29]. Under the action of protective film, the crack initiation time remains basically unchanged. With the increase of stress, the propagation time of the crack is obviously delayed, and the change trend of the capacitance arc of the whole process and the polarization resistance-time curve are basically consistent with the situation without the addition of the corrosion inhibitor. Therefore, SDBS mainly attenuates stress corrosion by reducing the corrosion.

4.3. Analysis of Corrosion Inhibition Mechanism of New Corrosion Inhibitor. Figure 17 shows the schematic diagram of the corrosion inhibition mechanism of new corrosion inhibitor. The new corrosion inhibitor is a Gemini surfactant, which belongs to anodic adsorption film-type corrosion inhibitor [16].

At the stage of crack initiation, ammonium ions are electrostatically adsorbed on the surface of the aluminum alloy, and new inhibitors are aligned on the metal surface to form a monomolecular film, which slows the dissolution of the metal. 
During the crack propagation stage, the new corrosion inhibitor is rapidly adsorbed on the exposed metal. At the crack propagation site, the inhibitor concentration gradually increases, the single molecule film gradually becomes dense, the crack propagation is suppressed, and the crack propagation time is delayed.

\section{Conclusion}

A new corrosion inhibitor was synthesized. The effect of three corrosion inhibitors on the crack initiation, and propagation of 7A04 aluminum alloy during the SSRT process was studied by combination of EIS and phase shift. The feasibility of this novel method to predict crack initiation and obvious propagation time is proved by SEM, EDS, and metallographic experiments. The inhibition mechanism of three types of corrosion inhibitors is inferred. The results are as follows:

(1) The results of EIS show that the tensile stage is divided into four periods: metal dissolution, crack initiation, dynamic equilibrium, and crack propagation. The phase shift method shows that the moment when the phase shift difference at $10 \mathrm{~Hz}, 100 \mathrm{~Hz}$, and $1000 \mathrm{~Hz}$ peaks is the moment when the crack initiation appears and obvious propagation time of aluminum alloys. Combining the two methods shows that sodium succinate effectively inhibits the crack initiation and propagation. New corrosion inhibitor and SDBS effectively inhibit the crack propagation, but not the crack initiation. Effects of three corrosion inhibitors are as follows: sodium succinate $>$ new corrosion inhibitor $>$ SDBS. The accuracy of the experimental data is confirmed by KKT.

(2) The inhibition mechanism of the three inhibitors is inferred. (1) The unbonded electrons in sodium succinate interact with the empty orbital of aluminum ion to form a coordination bond to adsorb on the surface of aluminum. (2) The alkyl sulfonic acid ions in SDBS form a protective film on the surface of positively charged aluminum. (3) At the stage of crack initiation, the quaternary ammonium salt group in the new corrosion inhibitor adsorbs on the surface of aluminum alloy to form a monomolecular layer. At the stage of crack propagation, the concentration of new corrosion inhibitor gradually increases at the crack propagation site, the single molecule film gradually becomes dense, the crack propagation is suppressed, and the crack propagation time is delayed.

\section{Data Availability}

The raw/processed data required to reproduce these findings cannot be shared at this time as the data also form part of an ongoing study.

\section{Conflicts of Interest}

The authors declare that they have no conflicts of interest.

\section{Acknowledgments}

This work was funded by the Tianjin Municipal Education Commission Scientific Research Project (2019KJ136) and Fundamental Research Funds for the Central Universities (FRFCU, Grant no. 3122014H006).

\section{References}

[1] N. J. H. Holroyd and G. M. Scamans, "Crack propagation during sustained-load cracking of $\mathrm{Al}-\mathrm{Zn}-\mathrm{Mg}-\mathrm{Cu}$ aluminum alloys exposed to moist air or distilled water," Metallurgical and Materials Transactions A, vol. 42, no. 13, pp. 3979-3998, 2011.

[2] M. C. Petit, M. Cid, M. Puiggali, and Z. Amor, "An impedance study of the passivity breakdown during stress corrosion cracking phenomena," Corrosion Science, vol. 31, pp. 491-496, 1990.

[3] R.-W. Bosch, "Electrochemical impedance spectroscopy for the detection of stress corrosion cracks in aqueous corrosion systems at ambient and high temperature," Corrosion Science, vol. 47, no. 1, pp. 125-143, 2005.

[4] S. Zhao, K. Arioka, and L.-P. Sergio, "A mechanistic study of SCC in alloy 600 through high-resolution characterization," Corrosion Science, vol. 132, pp. 244-259, 2018.

[5] J. Seong, G. Frankel, and N. Sridhar, "Inhibition of stress corrosion cracking of sensitized AA5083," Corrosion, vol. 72, no. 2, pp. 284-296, 2016.

[6] Y. Fang, B. Suganthan, and R. P. Ramasamy, "Electrochemical characterization of aromatic corrosion inhibitors from plant extracts," Journal of Electroanalytical Chemistry, vol. 840, pp. 74-83, 2019.

[7] M. Mohammad, A. R. Tehrani-Bagha, E. Alibakhshi et al., "Corrosion of mild steel in hydrochloric acid solution in the presence of two cationic gemini surfactants with and without hydroxyl substituted spacers," Corrosion Science, vol. 137, pp. 62-75, 2018.

[8] M. D. Rifat, S. G. Tayser, A. A. Al-Amiery, and A. A. H. Kadhum, "Inhibitive impacts extract of Citrus aurantium leaves of carbon steel in corrosive media corrosive media," Green Chemistry Letters and Reviews, vol. 11, no. 4, pp. 559-566, 2018.

[9] T. A. Salman, K. F. Al-Azawi, I. M. Mohammed et al., "Experimental studies on inhibition of mild steel corrosion by novel synthesized inhibitor complemented with quantum chemical calculations," Results in Physics, vol. 10, pp. 291-296, 2018.

[10] A. Ahmeda, H. O. A. Mohammed, A. A. Thamer et al., "Electrochemical studies of novel corrosion inhibitor for mild steel in $1 \mathrm{M}$ hydrochloric acid," Results in Physics, vol. 9, pp. 978-981, 2018.

[11] A. J. Qusay, S. Z. Dhafer, D. S. Rawaa et al., "Synthesis, characterization, and corrosion inhibition potential of novel thiosemicarbazone on mild steel in sulfuric acid environment," Coatings, vol. 9, no. 11, p. 72, 2019.

[12] S. Malarvizhi and V. Balasubramanian, "Effects of welding processes and post-weld aging treatment on fatigue behavior of AA2219 aluminium alloy joints," Journal of Materials Engineering and Performance, vol. 20, no. 3, pp. 359-367, 2011.

[13] H. Li, H. Wang, X. Liang, Y. Wang, and H. Liu, "Effect of Sc and $\mathrm{Nd}$ on the microstructure and mechanical properties of Al-Mg-Mn alloy," Journal of Materials Engineering and Performance, vol. 21, no. 1, pp. 83-88, 2012. 
[14] G. R. Gang and Z. Lin, "Study on synthesis of gemini surfactants with tri-quaternary double chain ammonium salt," Journal of Yangtze University (Natural Science Edition), vol. 7, no. 2, pp. 17-20, 2010.

[15] C. T. Gong and C. Z. Gang, "Synthesis and properties of novel gemini cationic surfactants (2) - synthesis of polyalkyl quaternary ammonium salts from dodecylamine and epichlorohydrin," Daily Chemical Industry, vol. 31, no. 4, pp. 36-38, 2011.

[16] D. Juan, J. Shuai, Y. Fan et al., "The preparation of a novel corrosion inhibitor and its corrosion inhibition behavior on $2024 \mathrm{Al}-\mathrm{Cu}-\mathrm{Mg}$ alloy in acid solution," Journal of Surfactants and Detergents, vol. 22, no. 4, pp. 833-843, 2019.

[17] R. B. Mears, R. H. Brown, and E. H. Dix, "Symposium on stress corrosion cracking of metal," ASTM and AIME, vol. 329, pp. 323-340, 1944.

[18] X. Q. Meng, Experimental Study on Stress Corrosion and Corrosion Fatigue Characteristics of Aluminum Alloy Materials, Shanghai Jiaotong University, Shanghai, China, 2012.

[19] B. A. Bouwkamp, Equivalent Circuit, Computer Assisted Electrochemical Ac-Immittance Data Analysis System, University of Twente, Enschede, Netherlands, 1995.

[20] J. Neshati, B. Adib, and A. Sardashti, "Stress corrosion cracking detection of sensitized stainless steel 304 in chloride media by using electrochemical impedance spectroscopy (EIS)," Journal of Petroleum Science and Technology, vol. 2, no. 1, pp. 55-60, 2012.

[21] G. Q. Wei, Y. X. Wang, and Y. X. Zhao, "Study on membrane assembly electrode of solid polymer electrolyte water electrolysis by electrochemical impedance spectroscopy," Renewable Energy Resources, vol. 31, no. 5, pp. 109-114, 2013.

[22] P. Lenfsfeld, J. A. Juarez-Islas, and W. A. Cassada, "Microstructure and mechanical behavior of spray deposited $\mathrm{Zn}$ modified 7xxx series Al alloy," International Journal of Rapid Solidification, vol. 8, no. 4, pp. 237-265, 1995.

[23] R. Mächler, P. J. Uggowitzer, C. Solenthaler, R. M. Pedrazzoli, and M. O. Speidel, "Structure, mechanical properties, and stress corrosion behaviour of high strength spray deposited 7000 series aluminium alloy," Materials Science and Technology, vol. 7, no. 5, pp. 447-451, 1991.

[24] T. Alldo, E. J. Lavernia, and N. J. Grant, "A TEM study of the microstructures of A modified 7075 and X2020 aluminum alloys produced by liquid dynamic compaction," Materials Letters, vol. 5, no. 1-2, pp. 17-28, 1995.

[25] A. H. Omar, "Corrosion inhibition studies of copper in highly concentrated $\mathrm{NaCl}$ solutions," Journal of Applied Electrochemistry, vol. 37, no. 8, pp. 933-940, 2007.

[26] H. Tavakoli, T. Shahrabi, and M. G. Hosseini, "Synergistic effect on corrosion inhibition of copper by sodium dodecylbenzenesulphonate (SDBS) and 2-mercaptobenzoxazole," Materials Chemistry and Physics, vol. 109, no. 2-3, pp. 281-286, 2008.

[27] D. Huang, J. Hu, G.-L. Song, and X. Guo, "Inhibition effect of inorganic and organic inhibitors on the corrosion of $\mathrm{Mg}$ $10 \mathrm{Gd}-3 \mathrm{Y}-0.5 \mathrm{Zr}$ alloy in an ethylene glycol solution at ambient and elevated temperatures," Electrochimica Acta, vol. 56, no. 27, pp. 10166-10178, 2011.

[28] I. A. Kartsonakis, S. G. Stanciu, A. A. Matei et al., "Evaluation of the protective ability of typical corrosion inhibitors for magnesium alloys towards the Mg ZK30 variant," Corrosion Science, vol. 100, pp. 194-208, 2015.

[29] B. Zhou, Y. Wang, and Y. Zuo, "Evolution of the corrosion process of AA 2024-T3 in an alkaline $\mathrm{NaCl}$ solution with sodium dodecylbenzenesulfonate and lanthanum chloride inhibitors," Applied Surface Science, vol. 357, pp. 735-744, 2015. 